\title{
Hidden Boron Catalysis: Nucleophile-Promoted Decomposition of HBpin
}

Andrew D. Bage, ${ }^{\S}$ Thomas A. Hunt, ${ }^{\not}$ Stephen P. Thomas ${ }^{*}$

${ }^{\S}$ EaStCHEM School of Chemistry, University of Edinburgh, David Brewster Road, Edinburgh, EH9 3FJ, United Kingdom.

${ }^{\star}$ Medicinal Chemistry, Early Oncology, AstraZeneca, Unit 310, Cambridge Science Park, Milton Road, Cambridge, CB4 0WG, United Kingdom.

*stephen.thomas@ed.ac.uk

\section{Supporting Information}




\section{Contents}

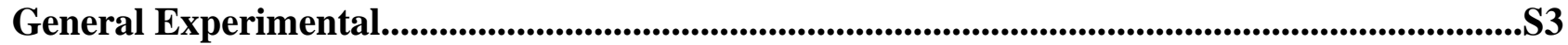

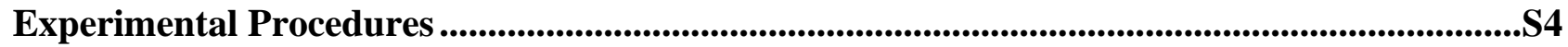

Quantifying the Nucleophile-Promoted Decomposition of HBpin by ${ }^{11}$ B NMR Spectroscopy......S4

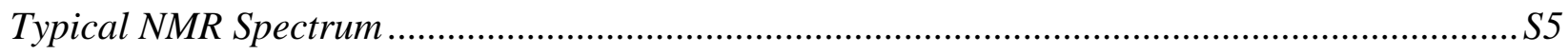

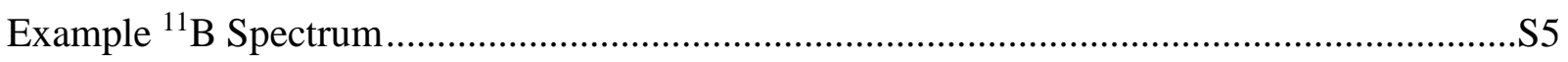

Preparation of bis-borane tetramethylethylenediamine complex, $\left(\mathrm{H}_{3} \mathrm{~B}\right)_{2} \cdot \mathrm{TMEDA}$......................S7

Preparation of lithium 4,4,5,5-tetramethyl-2-(1-phenylethoxy)-1,3,2-dioxaborolan-2-uide 8......S8

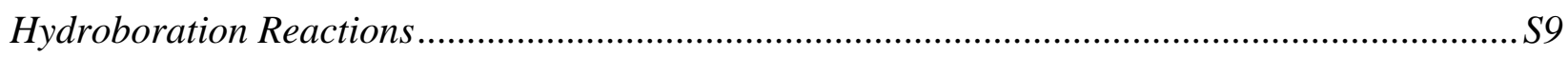

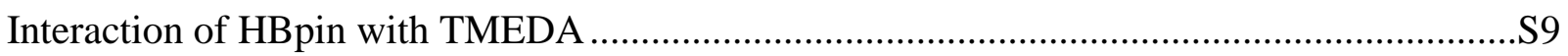

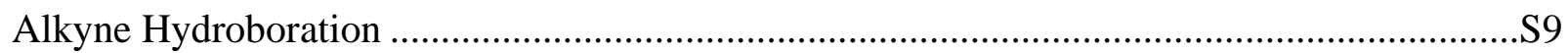

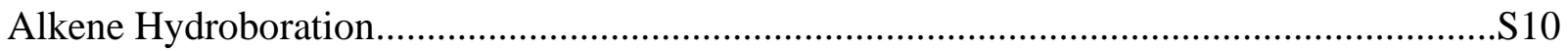

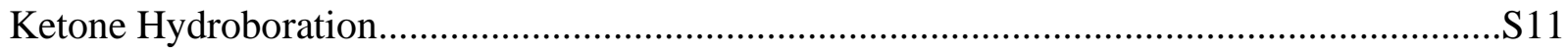

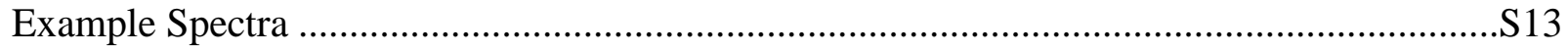

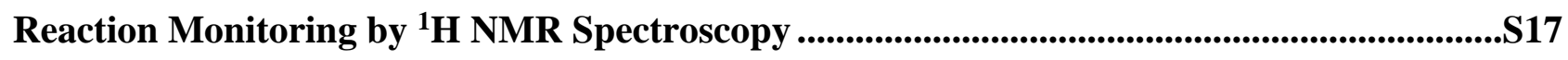

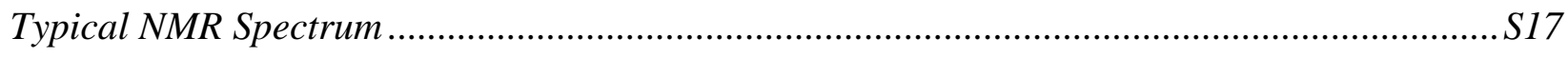

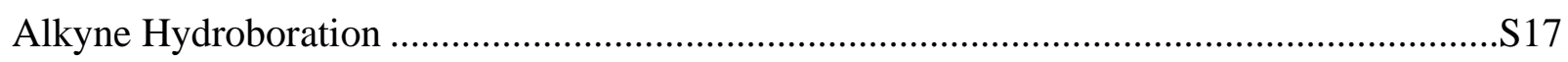

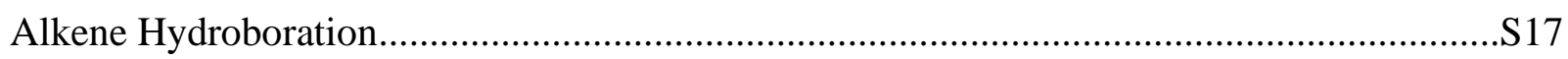

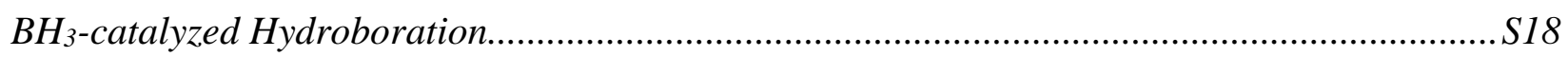

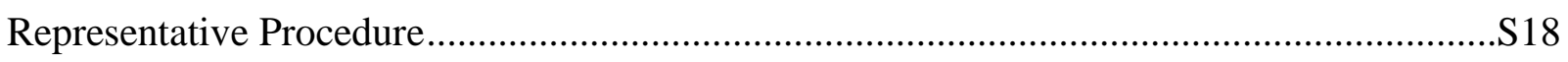

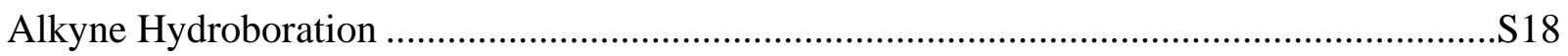

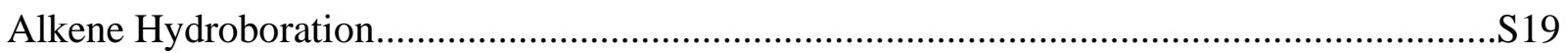

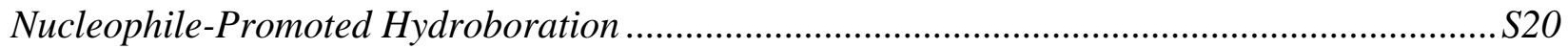

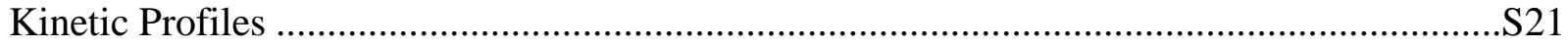

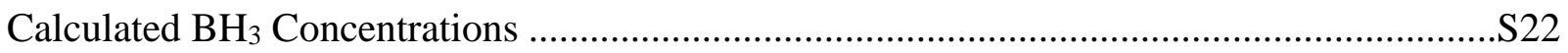

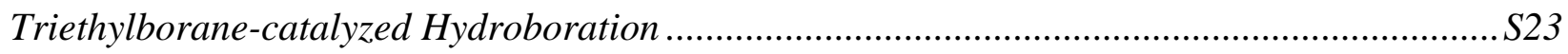

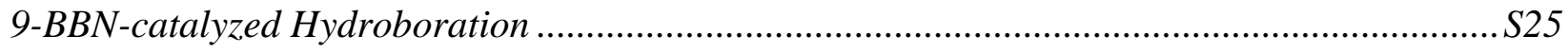

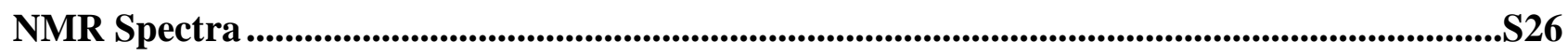

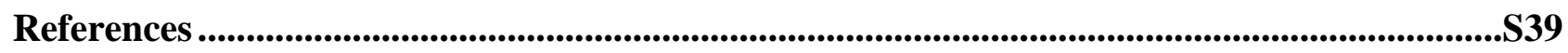




\section{General Experimental}

Reaction Setup: All reactions were performed in oven $\left(180{ }^{\circ} \mathrm{C}\right)$ and/or flamed-dried glassware under an atmosphere of anhydrous argon or nitrogen, unless otherwise indicated. All airand moisture sensitive reactions were carried out using standard vacuum line and Schlenk techniques, or in a glovebox with a purified argon atmosphere. All glassware was cleaned using base (KOH, $\left.{ }^{i} \mathrm{PrOH}\right)$ and acid $\left(\mathrm{HCl}_{\mathrm{aq}}\right)$ baths. All reported reaction temperatures correspond to external oil bath temperatures. Room temperature (rt) was approximately $18{ }^{\circ} \mathrm{C}$.

NMR Spectroscopy: ${ }^{1} \mathrm{H},{ }^{7} \mathrm{Li},{ }^{13} \mathrm{C}$ and ${ }^{11} \mathrm{~B}$ NMR spectra were recorded on Bruker Avance III 400 and $500 \mathrm{MHz}$; Bruker Avance I $600 \mathrm{MHz}$ spectrometers. Chemical shifts are reported in parts per million (ppm). ${ }^{1} \mathrm{H}$ and ${ }^{13} \mathrm{C}$ NMR spectra were referenced to the residual solvent peak $\left(\mathrm{CDCl}_{3}\right.$ : 7.26 ppm, 77.00 ppm; $\mathrm{C}_{6} \mathrm{D}_{6}: 7.16$ ppm, $128.06 \mathrm{ppm}$; $h_{8}$-toluene: $\left.{ }^{13} \mathrm{C} 137.84 \mathrm{ppm}\right)$. Multiplicities are indicated by br. (broad), s (singlet), d (doublet), t (triplet), q (quartet), quin. (quintet), m (multiplet), app. (apparent). Coupling constants, $J$, are reported in Hertz and rounded to the nearest $0.1 \mathrm{~Hz}$.

Solvents: All solvents for air- and moisture sensitive techniques were obtained from an anhydrous solvent system (Innovative Technology).

Chemicals: All reagents were purchased from Sigma Aldrich, Alfa Aesar, Acros organics, Tokyo Chemical Industries UK, Fluorochem and Apollo Scientific, or synthesised within the laboratory. 


\section{Experimental Procedures}

Quantifying the Nucleophile-Promoted Decomposition of HBpin by ${ }^{11}$ B NMR Spectroscopy

$$
\begin{gathered}
\mathrm{H}-\text { Bpin } \quad \stackrel{\text { Nucleophile }}{\stackrel{\text { Toluene, } \mathrm{SMe}_{2}}{\longrightarrow}} \mathrm{BH}_{3} \\
\\
\begin{array}{c}
6{ }^{\circ} \mathrm{C}, 20 \mathrm{~min} . \\
\mathrm{Ar} \mathrm{atm} .
\end{array}
\end{gathered}
$$

For solid and liquid nucleophiles:

A stock solution of HBpin $(5.20 \mathrm{~mL}, 36.0 \mathrm{mmol})$ and dimethyl sulfide $(176 \mu \mathrm{L}, 2.40 \mathrm{mmol})$ in toluene $(4.80 \mathrm{~mL})$ was prepared under $\mathrm{N}_{2}$. A sample of the stock solution $(0.50 \mathrm{~mL}, 1.8 \mathrm{mmol} \mathrm{HB}$ pin) was added to an NMR tube under argon. A ${ }^{11}$ B NMR spectrum was recorded to give a baseline spectrum, then the nucleophile $(0.12 \mathrm{mmol})$ was added to the NMR tube under argon. The reaction was heated to $60{ }^{\circ} \mathrm{C}$ for 20 minutes, then a second ${ }^{11} \mathrm{~B}$ NMR spectrum was recorded. Comparison between the two spectra gave a conversion of $\mathrm{HBpin}_{\text {to }} \mathrm{BH}_{3}$ (See Table S1).

\section{For solution-based nucleophiles:}

The solvent was removed under reduced pressure to give solid samples for MeLi, MeMgBr and LDA. These were used in the same procedure as for the other solid nucleophiles (See Table S1). ${ }^{n} \mathrm{BuLi}$, ${ }^{n} \mathrm{Bu}_{2} \mathrm{Mg}$ and $\mathrm{NaHBEt}_{3}$ were redissolved in toluene to give $1.0 \mathrm{M}$ solutions. For these nucleophiles, a modified procedure was used:

A stock solution of HBpin $(2.60 \mathrm{~mL}, 18.0 \mathrm{mmol})$ and dimethyl sulfide (90 $\mu \mathrm{L}, 1.2 \mathrm{mmol})$ in toluene $(1.20 \mathrm{~mL})$ was prepared under $\mathrm{N}_{2}$. A sample of the stock solution $(0.38 \mathrm{~mL}, 1.8 \mathrm{mmol} \mathrm{HB}$ pin) was added to an NMR tube under argon. A nucleophile (1.0 M in toluene, $0.12 \mathrm{~mL}, 0.12 \mathrm{mmol}$ ) was added to the NMR tube under argon. A control sample was prepared by the same method except toluene $(0.12 \mathrm{~mL})$ was added in place of the nucleophile. The samples were heated to $60{ }^{\circ} \mathrm{C}$ for 20 minutes, then ${ }^{11} \mathrm{~B}$ NMR spectra were recorded. Comparison between the two spectra gave a conversion of HBpin to $\mathrm{BH}_{3}$. For the reaction which used ${ }^{n} \mathrm{BuLi},{ }^{13} \mathrm{C}$ and ${ }^{7} \mathrm{Li}$ NMR spectra were also recorded, and a second ${ }^{11} \mathrm{~B}$ NMR spectrum was recorded after 2 hours (See Table S1). 


\section{Typical NMR Spectrum}

\section{${ }^{11}$ B NMR Shifts}

\begin{tabular}{|c|c|}
\hline Boron species & $\delta / \mathrm{ppm}$ \\
\hline $\mathrm{H}-\mathrm{Bpin}$ & $28(\mathrm{~d}, J=173 \mathrm{~Hz})$ \\
\hline & $\sim 5(\mathrm{~s})^{1}$ \\
\hline $\mathrm{H}_{3} \mathrm{~B} \cdot \mathrm{L}$ & $-12(\mathrm{q}, J=98 \mathrm{~Hz})$ \\
\hline $\mathrm{H}_{3} \mathrm{~B} \cdot \mathrm{SMe}_{2}$ & $-20(\mathrm{q}, J=97 \mathrm{~Hz})^{2}$ \\
\hline$\left[\mathrm{BH}_{4}\right]^{-}$ & $-39(\mathrm{p}, J=81 \mathrm{~Hz})^{3}$ \\
\hline$\left[\mathrm{B}_{2} \mathrm{H}_{7}\right]^{-}$or $\left[\mathrm{B}_{2} \mathrm{H}_{4} \mathrm{Et}_{3}\right]^{-}$ & $-27(\mathrm{q}, J=75 \mathrm{~Hz})^{4}$ \\
\hline $\mathrm{R}_{3} \mathrm{~B}$ & $\sim 85(s)^{3}$ \\
\hline$\left[\mathrm{H}_{2} \mathrm{Bpin}\right]^{-}$or $\mathrm{RH}_{2} \mathrm{~B} \cdot \mathrm{SMe}_{2}$ & $-6(\mathrm{t}, J=99 \mathrm{~Hz})^{5}$ \\
\hline $\mathrm{R}$-Bpin & $\sim 34(s)^{6}$ \\
\hline $\mathrm{B}_{2} \mathrm{pin}_{3}$ or ROBpin & $22(s)$ \\
\hline
\end{tabular}

Example ${ }^{11}$ B Spectrum
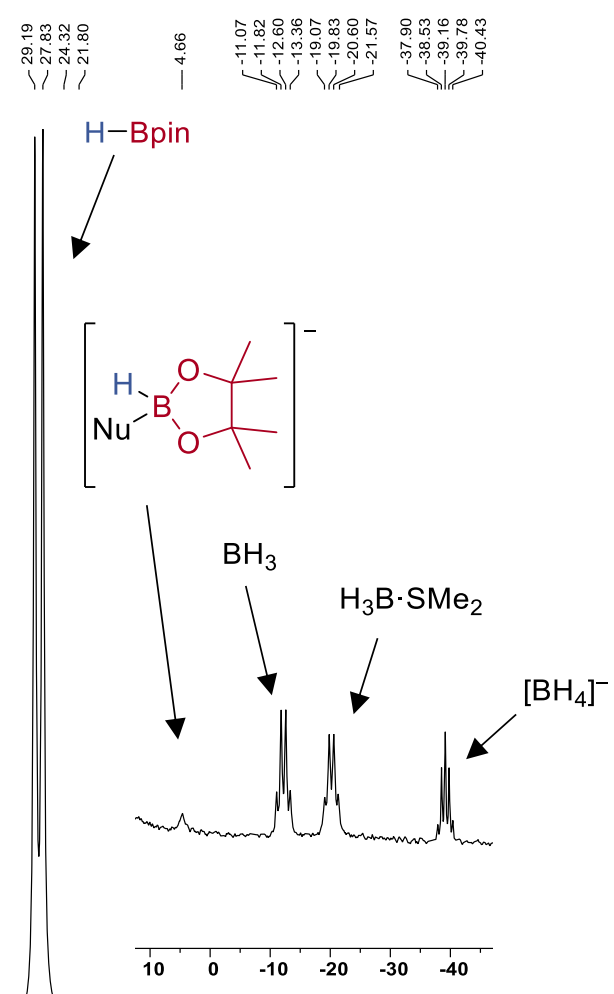

$\begin{array}{llllllllllllllllllllllllllllllllll}130 & 120 & 110 & 100 & 90 & 80 & 70 & 60 & 50 & 40 & 30 & 20 & 10 & 0 & -10 & -20 & -30 & -40 & -50 & -60 & -70 & -80 & -90 & -100 & -110 & -120 & -130\end{array}$

Figure S1. ${ }^{11} \mathrm{~B}$ NMR $\left(128 \mathrm{MHz}, h_{8}\right.$-toluene) of the reaction between $\mathrm{LiN}^{i} \mathrm{Pr}_{2}$ and $\mathrm{HBpin}$ 
Table S1. Quantifying Boron Species Formation from the Reaction of Nucleophiles with HBpin

\begin{tabular}{|c|c|c|c|c|c|c|c|c|c|}
\hline Nucleophile & $\begin{array}{l}\text { HBpin } \\
\text { (M) }\end{array}$ & $\begin{array}{c}\mathrm{B}_{2} \mathrm{pin}_{3} \text { and } \\
\text { ROBpin [B] } \\
\text { (M) }\end{array}$ & $\begin{array}{l}\mathrm{BH}_{3} \\
(\mathrm{M})\end{array}$ & $\begin{array}{c}{\left[\mathrm{BH}_{4}\right]^{-}} \\
(\mathrm{M})\end{array}$ & $\mathrm{R}_{3} \mathrm{~B}(\mathrm{M})$ & $\begin{array}{c}{\left[\mathrm{B}_{2} \mathrm{H}_{7}\right]^{-} \text {and }} \\
{\left[\mathrm{B}_{2} \mathrm{H}_{4} \mathrm{Et}_{3}\right]^{-}(\mathrm{M})}\end{array}$ & $\begin{array}{c}\text { RHBpin }^{-} \text {and } \\
\mathrm{RH}_{2} \mathrm{~B} \cdot \mathrm{SMe}_{2} \\
\text { (M) }\end{array}$ & $\begin{array}{l}\text { RBpin } \\
\text { (M) }\end{array}$ & Total (M) \\
\hline $\operatorname{Ti}\left(\mathrm{O}^{i} \operatorname{Pr}\right)_{4}$ & 5.66 & 1.59 & 0.30 & - & - & - & - & - & 7.55 \\
\hline $\mathrm{KO}^{t} \mathrm{Bu}$ & 7.19 & 0.25 & 0.02 & - & - & - & - & - & 7.46 \\
\hline $\mathrm{NaO}^{t} \mathrm{Bu}$ & 7.29 & 0.14 & 0.02 & - & - & - & - & - & 7.45 \\
\hline $\mathrm{LiO}^{t} \mathrm{Bu}$ & 7.25 & 0.21 & 0.03 & $<0.01$ & - & - & $<0.01$ & - & 7.49 \\
\hline $\mathrm{MeLi}$ & 7.15 & 0.03 & 0.02 & 0.01 & 0.03 & - & - & 0.27 & 7.51 \\
\hline $\mathrm{MeMgBr}$ & 7.33 & 0.08 & 0.01 & - & $<0.01$ & - & $<0.01$ & 0.09 & 7.51 \\
\hline $\mathrm{NaHBEt}_{3}$ & 7.22 & 0.15 & 0.03 & - & 0.37 & 0.03 & 0.03 & 0.21 & 8.04 \\
\hline $\mathrm{Na}\left[\mathrm{N}\left(\mathrm{SiMe}_{3}\right)_{2}\right]$ & 7.24 & 0.18 & 0.02 & - & - & - & - & - & 7.44 \\
\hline $\mathrm{LiN}^{i} \mathrm{Pr}_{2}$ & 7.25 & 0.15 & 0.06 & 0.02 & - & - & $<0.01$ & - & 7.48 \\
\hline $\mathrm{NaOH}$ & 7.41 & 0.06 & 0.01 & - & - & - & - & - & 7.48 \\
\hline${ }^{n} \mathrm{Bu}_{2} \mathrm{Mg}$ & 7.00 & 0.12 & 0.07 & 0.04 & 0.08 & 0.01 & $<0.01$ & 0.20 & 7.52 \\
\hline${ }^{n} \mathrm{BuLi}$ & 7.23 & 0.04 & 0.04 & 0.01 & 0.06 & - & 0.01 & 0.16 & 7.55 \\
\hline${ }^{n} \mathrm{BuLi}^{a}$ & 7.20 & 0.04 & 0.04 & 0.01 & 0.04 & - & 0.01 & 0.19 & 7.53 \\
\hline $\mathrm{LiAlH}_{4}$ & 6.84 & 0.05 & 0.18 & 0.36 & - & - & - & - & 7.43 \\
\hline $\mathrm{LiBH}_{4}$ & 7.36 & 0.12 & 0.01 & 0.01 & - & - & $<0.01$ & - & 7.50 \\
\hline NaOTf & 7.46 & 0.02 & 0.00 & - & - & - & - & - & 7.48 \\
\hline
\end{tabular}

- = not observed. ${ }^{a}$ After 2 hours. 
Preparation of bis-borane tetramethylethylenediamine complex, $\left(\mathrm{H}_{3} B\right)_{2} \cdot T M E D A$<smiles>CN(C)CCN(C)CCN(C)CCN(C)C</smiles>

$N, N, N^{\prime}, N^{\prime}$-Tetramethylethylenediamine (TMEDA) $(3.0 \mathrm{~mL}, 20 \mathrm{mmol})$ was added dropwise to a solution of $\mathrm{H}_{3} \mathrm{~B} \cdot \mathrm{SMe}_{2}(1.9 \mathrm{~mL}, 20 \mathrm{mmol})$ in toluene $(5 \mathrm{~mL})$ under $\mathrm{N}_{2}$. A white precipitate rapidly formed. The toluene and dimethyl sulfide were removed under reduced pressure to give $\left(\mathrm{H}_{3} \mathrm{~B}\right)_{2} \cdot$ TMEDA $(1.5 \mathrm{~g}, 10 \mathrm{mmol}, 52 \%)$ as a white amorphous solid.

${ }^{1}$ H NMR: $\quad\left(500 \mathrm{MHz}, \mathrm{CDCl}_{3}\right)$

3.16 (s, 4H), 2.64 (s, 12H), 1.57 (app. dd, $J=190.9,85.8 \mathrm{~Hz}, 6 \mathrm{H}$ ).

Mono-adduct: $2.86(\mathrm{dd}, J=8.1,6.1 \mathrm{~Hz}, 4 \mathrm{H}), 2.62(\mathrm{~s}, 6 \mathrm{H}), 2.24(\mathrm{~s}, 6 \mathrm{H})$.

[Free TMEDA: 2.37 (s, 4H), $2.23(\mathrm{~s}, 12 \mathrm{H})$.]

${ }^{13}$ C NMR: $\quad\left(126 \mathrm{MHz}, \mathrm{CDCl}_{3}\right)$

$58.9,52.8$.

Mono-adduct: $61.8,54.2,51.9,45.7$

[Free TMEDA: 57.6, 45.8]

11B NMR: $\quad\left(160 \mathrm{MHz}, \mathrm{CDCl}_{3}\right)$

$-10.62(\mathrm{q}, J=98.4 \mathrm{~Hz})$.

Data were in accordance with those previously reported. ${ }^{7-8}$ 
Preparation of lithium 4,4,5,5-tetramethyl-2-(1-phenylethoxy)-1,3,2-dioxaborolan-2-uide 8

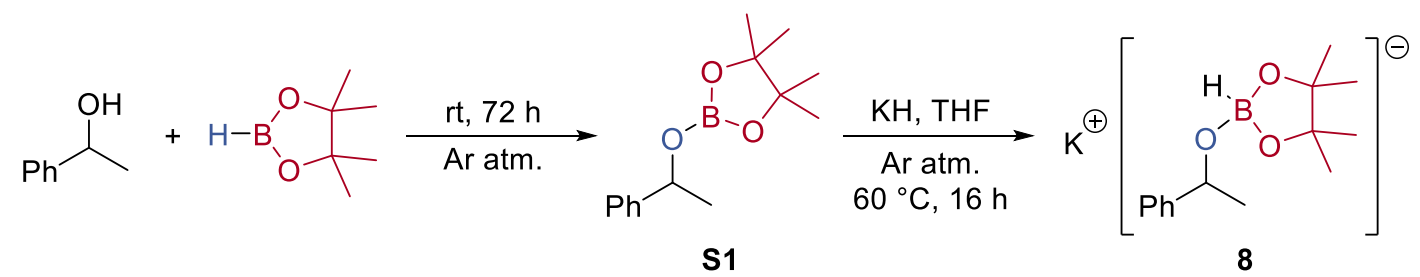

1-Phenylethanol (1.20 mL, $10.0 \mathrm{mmol})$ was added dropwise to a flask of HBpin (2.04 mL, $14.0 \mathrm{mmol})$ under argon with stirring. The reaction was left to stir at room temperature for 72 hours. Excess HBpin was removed under reduced pressure to give 4,4,5,5-tetramethyl-2-(1-phenylethoxy)-1,3,2dioxaborolane S1 (2.29 g, $9.23 \mathrm{mmol}, 92.3 \%)$ as a colourless oil and was used without purification.

1H NMR: $\quad\left(500 \mathrm{MHz}, \mathrm{C}_{6} \mathrm{D}_{6}\right)$

$7.40-7.34(\mathrm{~m}, 2 \mathrm{H}), 7.17-7.11(\mathrm{~m}, 2 \mathrm{H}), 7.07-7.03(\mathrm{~m}, 1 \mathrm{H}), 5.42(\mathrm{q}, J=6.5 \mathrm{~Hz}$, $1 \mathrm{H}), 1.46(\mathrm{~d}, J=6.5 \mathrm{~Hz}, 3 \mathrm{H}), 1.03(\mathrm{~s}, 6 \mathrm{H}), 1.00(\mathrm{~s}, 6 \mathrm{H})$.

${ }^{13}$ C NMR: $\quad\left(126 \mathrm{MHz}, \mathrm{C}_{6} \mathrm{D}_{6}\right)$ $145.4,128.6,127.4,125.7,82.5,73.0,25.8,24.7,24.6$.

11B NMR: $\quad\left(160 \mathrm{MHz}, \mathrm{C}_{6} \mathrm{D}_{6}\right)$ 22.66 (s).

Data were in accordance with those previously reported. ${ }^{9}$

Using a modified procedure based on Docherty et al., ${ }^{10}$ a sample of 4,4,5,5-tetramethyl-2-(1phenylethoxy)-1,3,2-dioxaborolane $\mathbf{S 1}$ (25 mg, $0.10 \mathrm{mmol}$ ) was dissolved in THF (0.50 mL) under argon and reacted with potassium hydride $(40 \mathrm{mg}, 1.0 \mathrm{mmol})$, heating at $60{ }^{\circ} \mathrm{C}$ for 16 hours. The reaction was allowed to cool to room temperature and filtered through glass wool to give a solution of lithium 4,4,5,5-tetramethyl-2-(1-phenylethoxy)-1,3,2-dioxaborolan-2-uide 8 (0.20 M in THF).

${ }^{11}$ B NMR: $\quad\left(160 \mathrm{MHz}, h_{8}-\mathrm{THF}\right)$

20.61 (br. s), 6.50 (s), 5.27 (s).

Data were in accordance with those previously reported. ${ }^{1,10}$ 


\section{Hydroboration Reactions}

For the hydroboration reactions, solution-based nucleophiles were used as purchased, i.e. not transferred into toluene and without adjusting the molarity of the solution.

Interaction of HBpin with TMEDA

HBpin $(145 \mu \mathrm{L}, 1.0 \mathrm{mmol})$ and TMEDA $(150 \mu \mathrm{L}, 1.0 \mathrm{mmol})$ were added to a reaction vial under $\mathrm{N}_{2}$. The reaction mixture was dissolved in THF $(2 \mathrm{~mL})$ and heated to $60{ }^{\circ} \mathrm{C}$ with stirring for 20 minutes. No adduct formation was observed by ${ }^{11} \mathrm{~B}$ NMR spectroscopy.

Alkyne Hydroboration

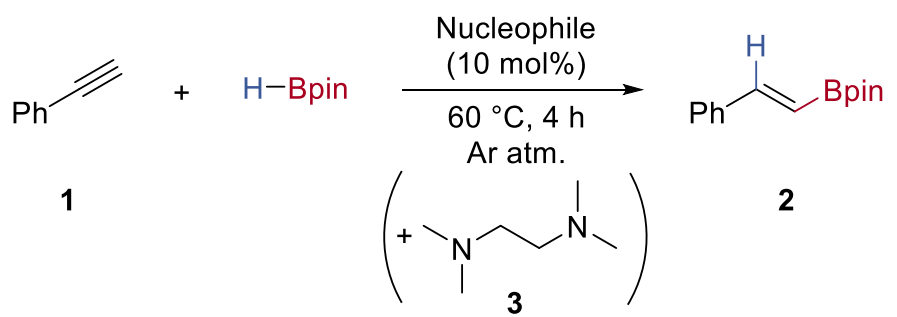

Pinacolborane $(0.22 \mathrm{~mL}, 1.5 \mathrm{mmol})$, nucleophile $(0.10 \mathrm{mmol})$, TMEDA 3 (0.015 mL, $0.10 \mathrm{mmol})$ and phenylacetylene $1(0.11 \mathrm{~mL}, 1.0 \mathrm{mmol})$ were reacted under argon for 4 hours at $60{ }^{\circ} \mathrm{C}$ with stirring. The reaction mixture was cooled to room temperature and quenched by the addition of an internal standard [1,3,5-trimethoxybenzene $(0.10 \mathrm{mmol})$ in dichloromethane $(1.0 \mathrm{~mL})]$. The yield of alkenylboronic ester 2 was determined by ${ }^{1} \mathrm{H}$ NMR spectroscopy $\left(\mathrm{CDCl}_{3}\right)$ by comparison of the diagnostic peak $[6.18(\mathrm{~d}, J=18.4 \mathrm{~Hz}, 1 \mathrm{H})]$ with the internal standard $[6.10(\mathrm{~s}, 3 \mathrm{H})]$, using an average of two runs. Data were in accordance with those previously reported. ${ }^{11}$ (See Figures S2-S4).

Table S2. Nucleophile-Mediated Phenylacetylene 1 Hydroboration and Hydroboration Inhibition with TMEDA $\mathbf{3}$

\begin{tabular}{ccc}
\hline Nucleophile & 2 without TMEDA (\%) & 2 with TMEDA (\%) \\
\hline None $\left(\mathrm{H}_{3} \mathrm{~B} \cdot \mathrm{SMe}_{2}\right)$ & 94 & 10 \\
None $\left(\mathrm{H}_{3} \mathrm{~B} \cdot \mathrm{TMEDA}\right)$ & 5 & $\mathrm{~N} / \mathrm{A}$ \\
$\mathrm{NaHBEt}_{3}$ & 61 & $3^{a}$ \\
$\mathrm{LiAlH}_{4}$ & 51 & 3 \\
$\mathrm{NaOH}^{\mathrm{NaO}}{ }^{t} \mathrm{Bu}$ & 41 & 1 \\
\hline
\end{tabular}




\begin{tabular}{ccc}
\hline $\mathrm{Na}\left[\mathrm{N}\left(\mathrm{SiMe}_{3}\right)_{2}\right]$ & 29 & 0 \\
$\mathrm{MeMgBr}$ & 60 & 1 \\
${ }^{n} \mathrm{BuLi}$ & 53 & $1^{c}$ \\
$\mathrm{Ti}\left(\mathrm{O}^{i} \mathrm{Pr}\right)_{4}$ & 51 & $5^{c}$ \\
${ }^{n} \mathrm{Bu}_{2} \mathrm{Mg}$ & 81 & $11^{c}$ \\
\hline
\end{tabular}

${ }^{a} 60$ mol\% TMEDA. $^{b} 18$ hour reaction time. ${ }^{c} 30$ mol\% TMEDA.

Alkene Hydroboration

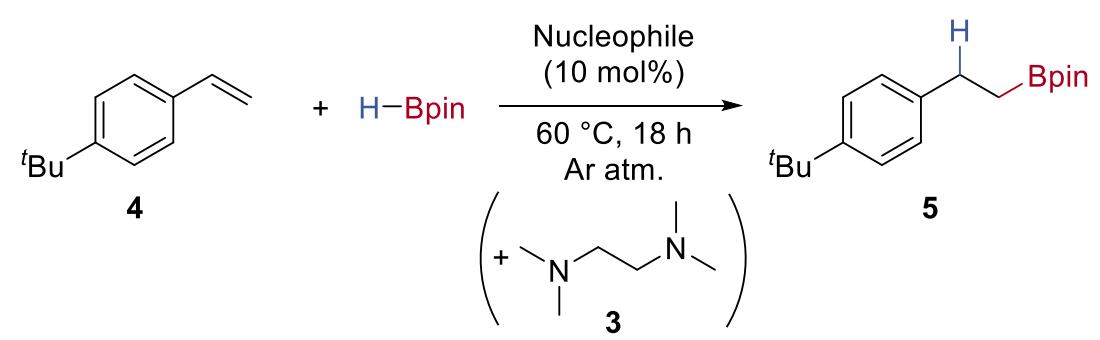

Pinacolborane $(0.22 \mathrm{~mL}, 1.5 \mathrm{mmol})$, nucleophile $(0.10 \mathrm{mmol})$, TMEDA 3 (0.030 mL, $0.20 \mathrm{mmol})$ and tert-butylstyrene $4(0.18 \mathrm{~mL}, 1.0 \mathrm{mmol})$ were reacted under argon for 18 hours at $60{ }^{\circ} \mathrm{C}$ with stirring. The reaction mixture was cooled to room temperature and quenched by the addition of an internal standard [1,3,5-trimethoxybenzene $(0.10 \mathrm{mmol})$ in dichloromethane or diethyl ether $(1.0$ $\mathrm{mL})]$. The yield of alkylboronic ester 5 was determined by ${ }^{1} \mathrm{H}$ NMR spectroscopy $\left(\mathrm{CDCl}_{3}\right)$ by comparison of the diagnostic peak $[2.74-2.69(\mathrm{~m}, 2 \mathrm{H})]$ with the internal standard $[6.10(\mathrm{~s}, 3 \mathrm{H})]$, using an average of two runs. Data were in accordance with those previously reported. ${ }^{12}$ (See Figures S5-S7).

Table S3. Nucleophile-Mediated tert-Butylstyrene 4 Hydroboration and Hydroboration Inhibition with TMEDA 3

\begin{tabular}{ccc}
\hline Nucleophile & 5 without TMEDA (\%) & 5 with TMEDA (\%) \\
\hline None $\left(\mathrm{H}_{3} \mathrm{~B} \cdot \mathrm{SMe}_{2}\right)$ & 67 & 5 \\
$\mathrm{NaHBEt}_{3}$ & 81 & 43 \\
$\mathrm{LiAlH}_{4}$ & 81 & 5 \\
$\mathrm{NaOH}$ & 28 & 7 \\
$\mathrm{NaO}{ }^{t} \mathrm{Bu}$ & 71 & 10 \\
$\mathrm{Na}\left[\mathrm{N}\left(\mathrm{SiMe}_{3}\right)_{2}\right]$ & 72 & 12 \\
$\mathrm{MeMgBr}$ & 55 & 21 \\
${ }^{n} \mathrm{BuLi}$ & 30 & 26 \\
${ }_{\mathrm{Ti}}\left(\mathrm{O}^{i} \mathrm{Pr}\right)_{4}$ & 73 & 10 \\
${ }^{n} \mathrm{Bu}{ }_{2} \mathrm{Mg}$ & 85 & 22
\end{tabular}


Ketone Hydroboration

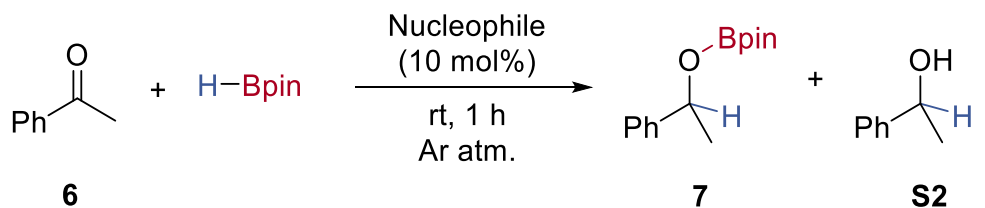

Pinacolborane $(0.22 \mathrm{~mL}, 1.5 \mathrm{mmol})$, nucleophile $(0.10 \mathrm{mmol})$ and acetophenone $6(0.12 \mathrm{~mL}, 1.0$ $\mathrm{mmol}$ ) were reacted under argon for 1 hour at room temperature with stirring. The reaction mixture was quenched by the addition of an internal standard [1,3,5-trimethoxybenzene $(0.10 \mathrm{mmol})$ in dichloromethane $(1.0 \mathrm{~mL})]$. The combined yield of alkoxyboronic ester 7 and alcohol $\mathbf{S 2}$ was determined by ${ }^{1} \mathrm{H}$ NMR spectroscopy $\left(\mathrm{CDCl}_{3}\right)$ by comparison of the diagnostic peaks [7: 5.25 (q, $J$ $=6.5 \mathrm{~Hz}, 1 \mathrm{H}) ; \mathbf{S 2}: 4.88(\mathrm{q}, J=6.5 \mathrm{~Hz}, 1 \mathrm{H})]$ with the internal standard $(\mathrm{s}, 3 \mathrm{H})$, using an average of two runs. Data were in accordance with those previously reported. ${ }^{13-14}$ (See Figures S8).

Table S4. Nucleophile-Mediated Acetophenone 6 Hydroboration

\begin{tabular}{cc}
\hline Nucleophile & $\mathbf{7 +} \mathbf{S} 2(\%)$ \\
\hline None $\left(\mathrm{H}_{3} \mathrm{~B} \cdot \mathrm{SMe}_{2}\right)$ & 32 \\
$\mathrm{NaHBEt}_{3}$ & $>95$ \\
$\mathrm{LiAlH}_{4}$ & $>95$ \\
$\mathrm{NaOH}$ & 34 \\
$\mathrm{NaO}{ }^{t} \mathrm{Bu}$ & $>95$ \\
$\mathrm{Na}\left[\mathrm{N}\left(\mathrm{SiMe}_{3}\right)_{2}\right]$ & $>95$ \\
$\mathrm{MeMgBr}$ & 91 \\
${ }^{n} \mathrm{BuLi}$ & 89 \\
$\mathrm{Ti}\left(\mathrm{O}^{i} \mathrm{Pr}\right)_{4}$ & 29 \\
${ }^{n} \mathrm{Bu}{ }_{2} \mathrm{Mg}$ & $>95$ \\
\hline
\end{tabular}<smiles>CC(=O)c1ccccc1</smiles>

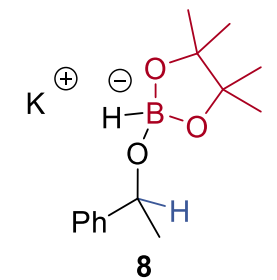

Pinacolborane (0.22 mL, $1.5 \mathrm{mmol}), 8(0.10 \mathrm{~mL}, 0.20 \mathrm{M}$ in THF, $0.040 \mathrm{mmol})$ and acetophenone 6 $(0.12 \mathrm{~mL}, 1.0 \mathrm{mmol})$ were reacted under argon for 1 hour at room temperature with stirring. The reaction mixture was quenched by the addition of an internal standard [1,3,5-trimethoxybenzene $(0.10$ $\mathrm{mmol})$ in dichloromethane $(1.0 \mathrm{~mL})]$. The combined yield of alkoxyboronic ester $\mathbf{7}$ and alcohol $\mathbf{S 2}$ (>95\%) was determined by ${ }^{1} \mathrm{H}$ NMR by spectroscopy $\left(\mathrm{CDCl}_{3}\right)$ by comparison of the diagnostic peak 
[7: $5.25(\mathrm{q}, J=6.5 \mathrm{~Hz}, 1 \mathrm{H}) ; \mathbf{S 2}: 4.88(\mathrm{q}, J=6.5 \mathrm{~Hz}, 1 \mathrm{H})]$ with the internal standard $(\mathrm{s}, 3 \mathrm{H})$, subtracting the catalyst loading. Data were in accordance with those previously reported. ${ }^{13-14}$ 
Example Spectra

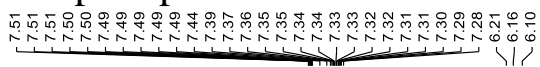

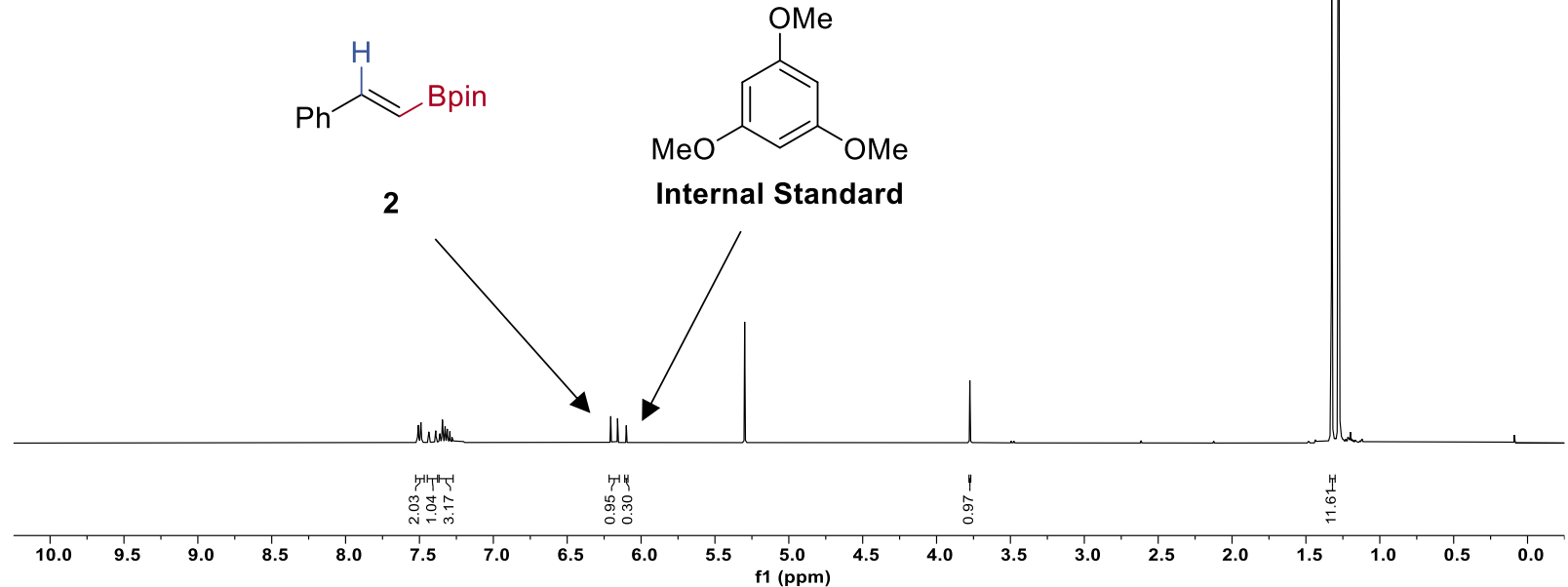

Figure S2. ${ }^{1} \mathrm{H}$ NMR (400 MHz, $\mathrm{CDCl}_{3}$ ) of the hydroboration of phenylacetylene 1 catalyzed by $\mathrm{H}_{3} \mathrm{~B} \cdot \mathrm{SMe}_{2}$.

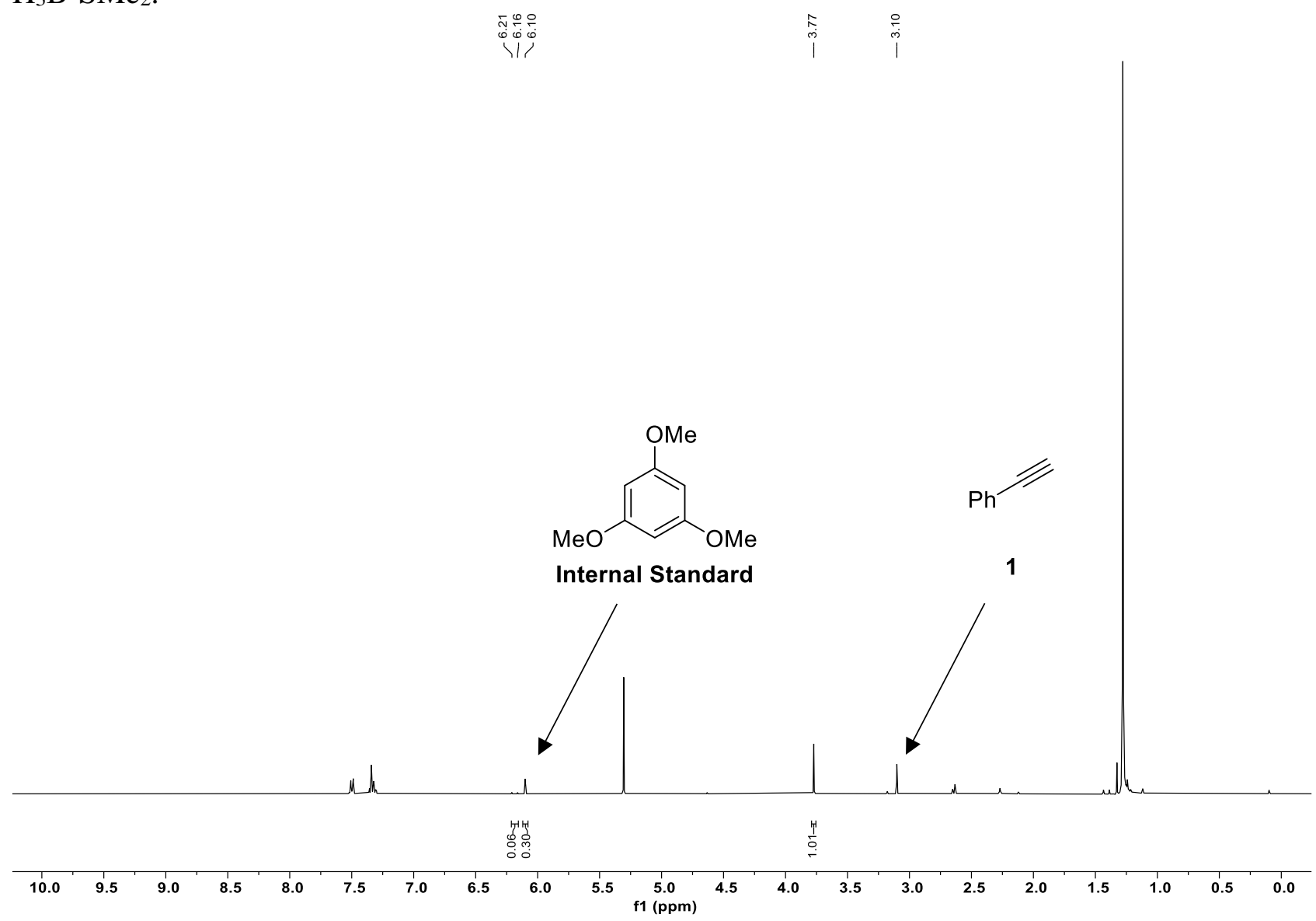

Figure S3. ${ }^{1} \mathrm{H}$ NMR $\left(400 \mathrm{MHz}, \mathrm{CDCl}_{3}\right)$ of the hydroboration of phenylacetylene 1 catalyzed by $\mathrm{H}_{3} \mathrm{~B} \cdot \mathrm{SMe}_{2}$, inhibited by TMEDA. 


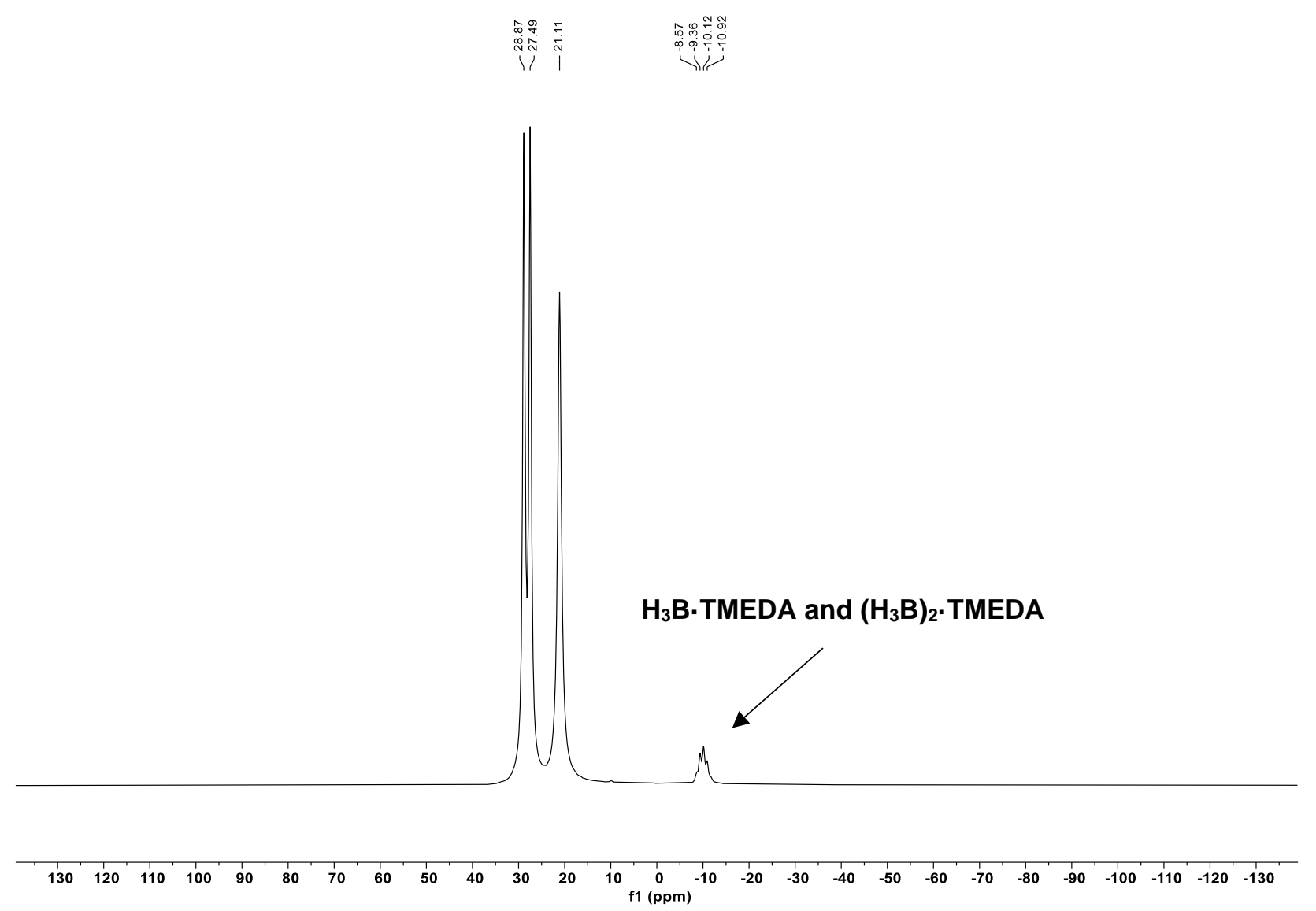

Figure S4. ${ }^{11} \mathrm{~B}$ NMR $\left(128 \mathrm{MHz}, \mathrm{CDCl}_{3}\right)$ of the hydroboration of phenylacetylene 1 catalyzed by $\mathrm{H}_{3} \mathrm{~B} \cdot \mathrm{SMe}_{2}$, inhibited by TMEDA.

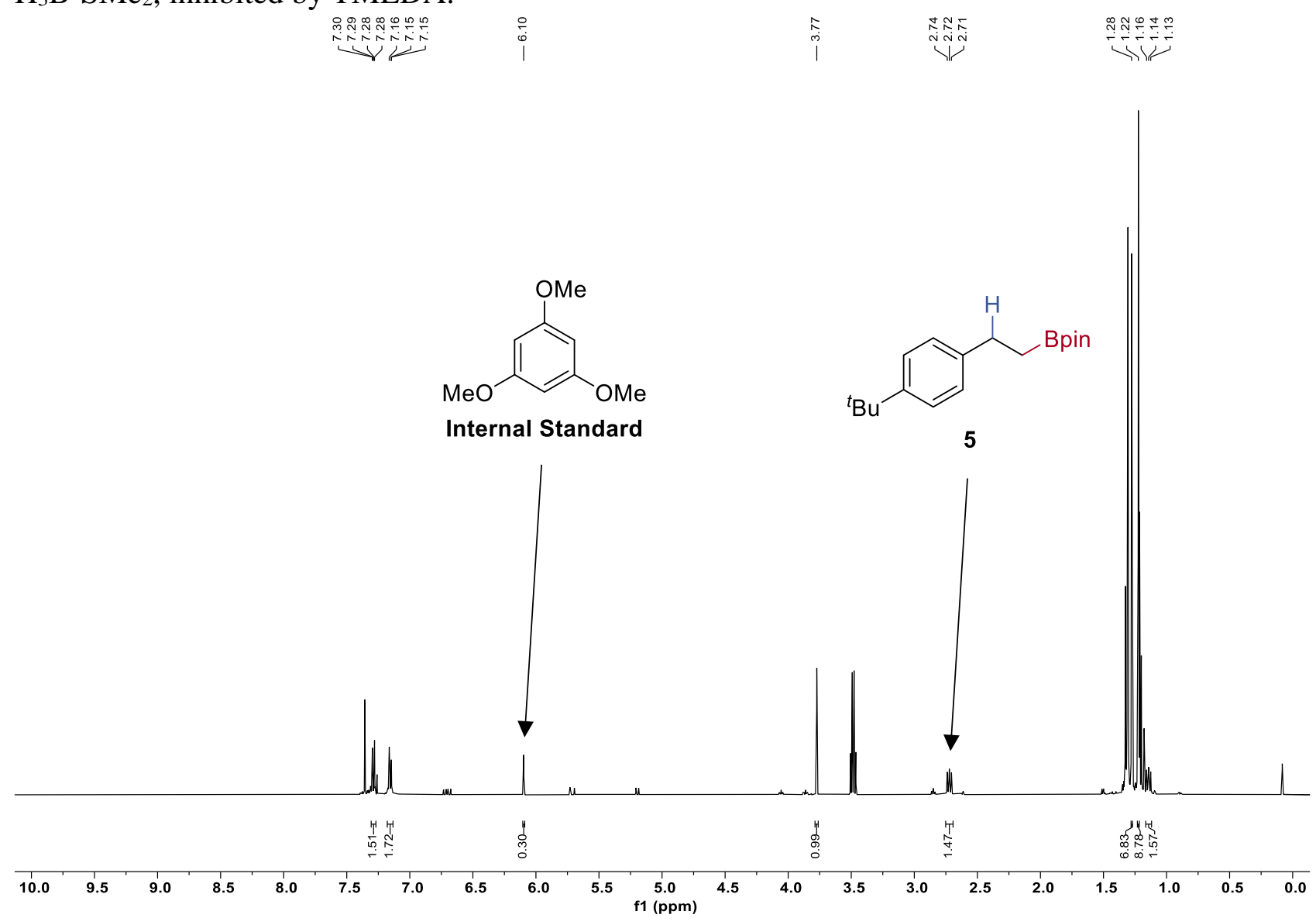

Figure S5. ${ }^{1} \mathrm{H}$ NMR $\left(500 \mathrm{MHz}, \mathrm{CDCl}_{3}\right)$ of the hydroboration of tert-butylstyrene 4 catalyzed by $\mathrm{H}_{3} \mathrm{~B} \cdot \mathrm{SMe}_{2}$. 


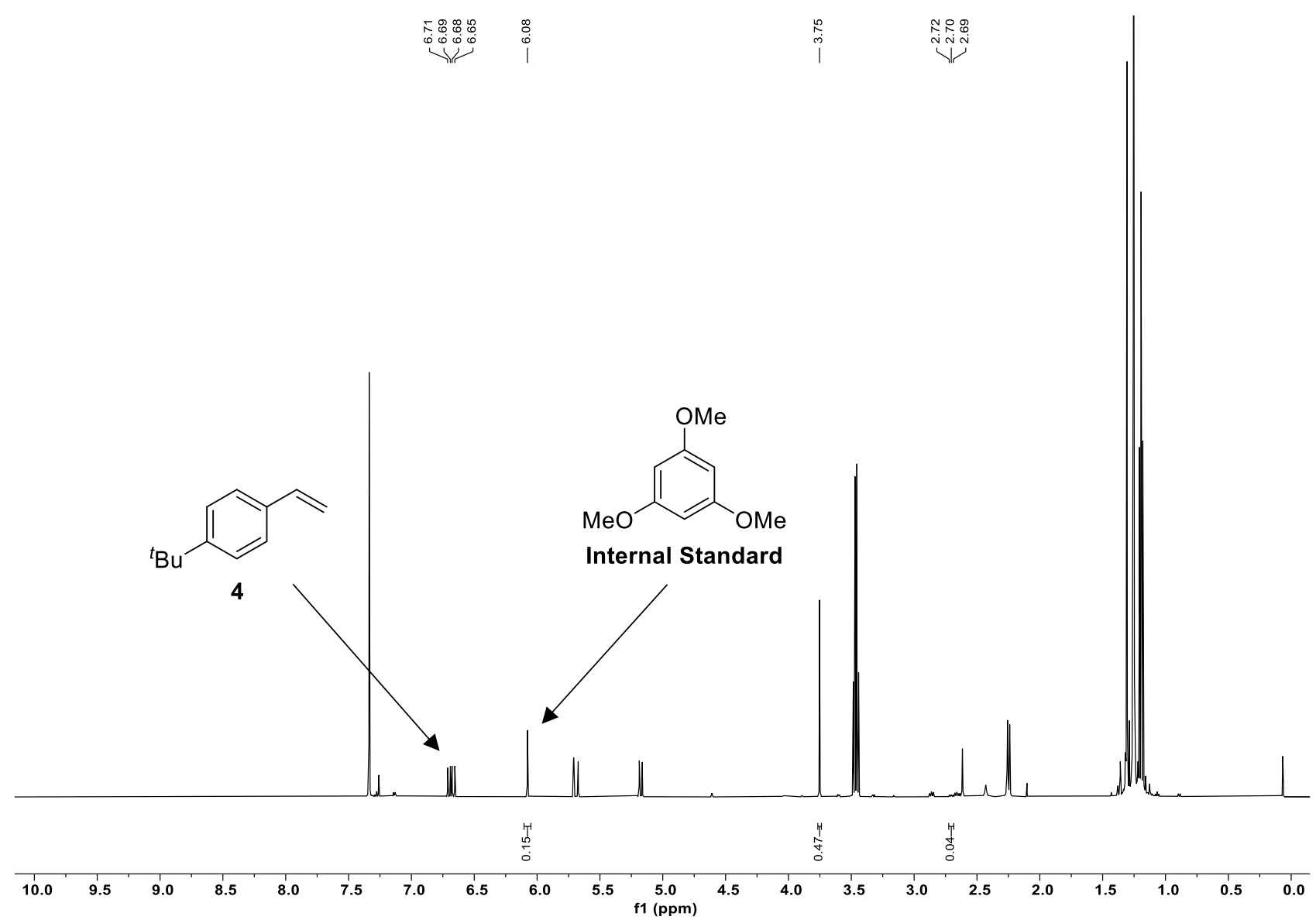

Figure S6. ${ }^{1} \mathrm{H}$ NMR $\left(500 \mathrm{MHz}, \mathrm{CDCl}_{3}\right)$ of the hydroboration of tert-butylstyrene 4 catalyzed by $\mathrm{H}_{3} \mathrm{~B} \cdot \mathrm{SMe}_{2}$, inhibited by TMEDA.

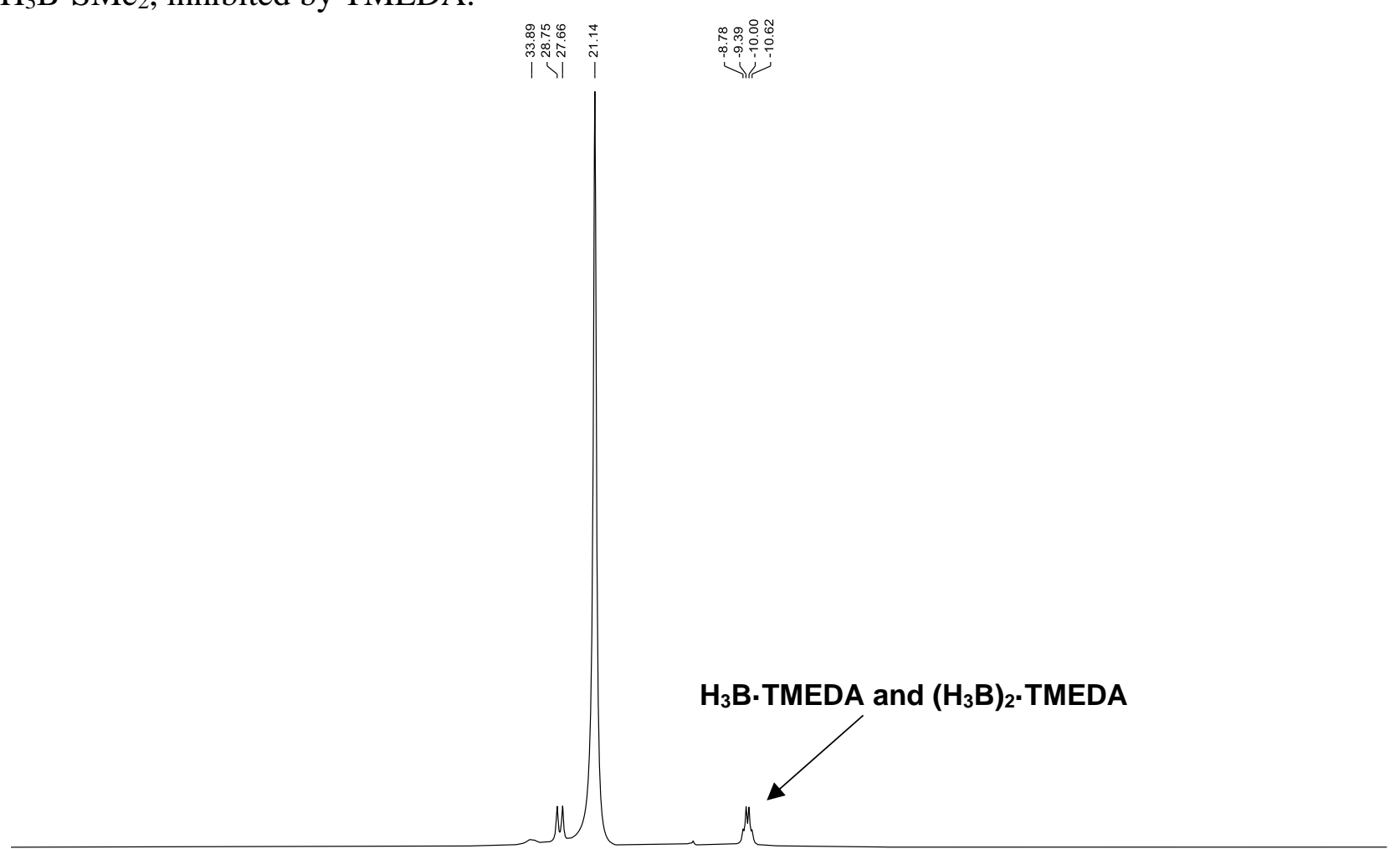

$\begin{array}{llllllllllllllllllllllllllllllllll}130 & 120 & 110 & 100 & 90 & 80 & 70 & 60 & 50 & 40 & 30 & 20 & 10 & 0 & -10 & -20 & -30 & -40 & -50 & -60 & -70 & -80 & -90 & -100 & -110 & -120 & -130\end{array}$

Figure S7. ${ }^{11} \mathrm{~B}$ NMR $\left(160 \mathrm{MHz}, \mathrm{CDCl}_{3}\right)$ of the hydroboration of tert-butylstyrene 4 catalyzed by $\mathrm{H}_{3} \mathrm{~B} \cdot \mathrm{SMe}_{2}$, inhibited by TMEDA. 


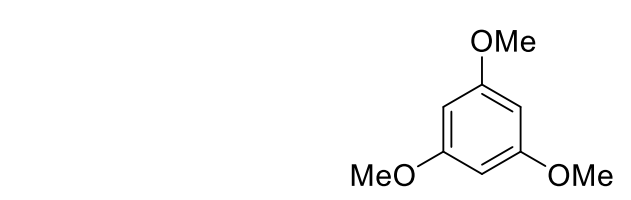

$\overbrace{\mathrm{O}-\mathrm{Bpin}}^{\mathrm{H}}$<smiles>CC(O)(I)c1ccccc1</smiles>

Internal Standard

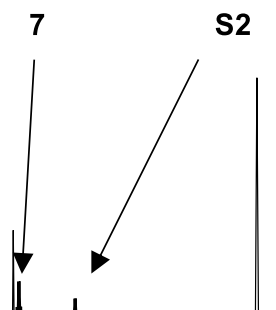

s2
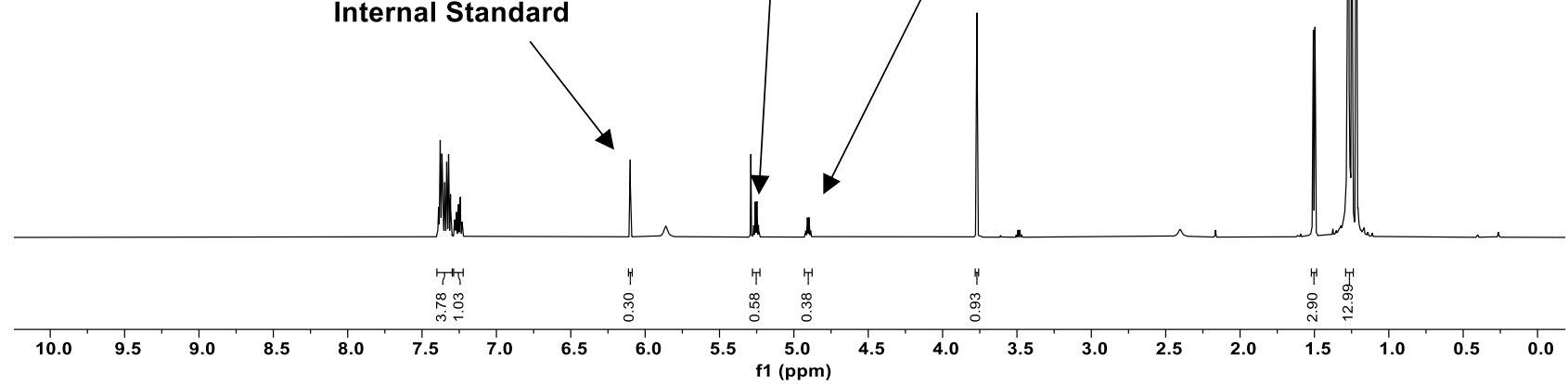

Figure S8. ${ }^{1} \mathrm{H} \mathrm{NMR}\left(600 \mathrm{MHz}, \mathrm{CDCl}_{3}\right)$ of acetophenone 6 mediated by $\mathrm{MeMgBr}$. 


\section{Reaction Monitoring by ${ }^{1} \mathrm{H}$ NMR Spectroscopy}

\section{Typical NMR Spectrum}

Alkyne Hydroboration

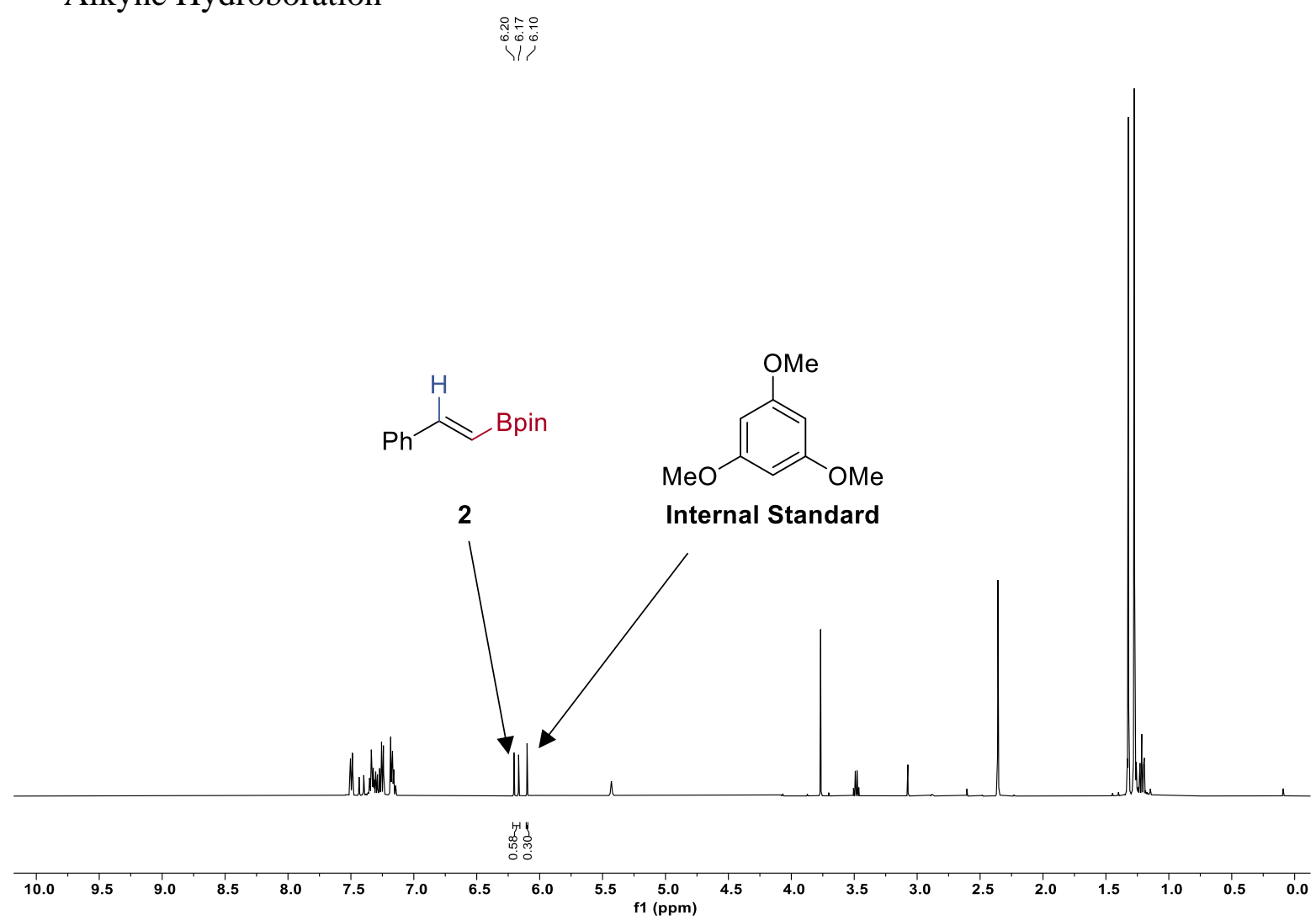

Figure S9. ${ }^{1} \mathrm{H}$ NMR spectrum during turnover, with diagnostic peaks of key species labelled.

Alkene Hydroboration
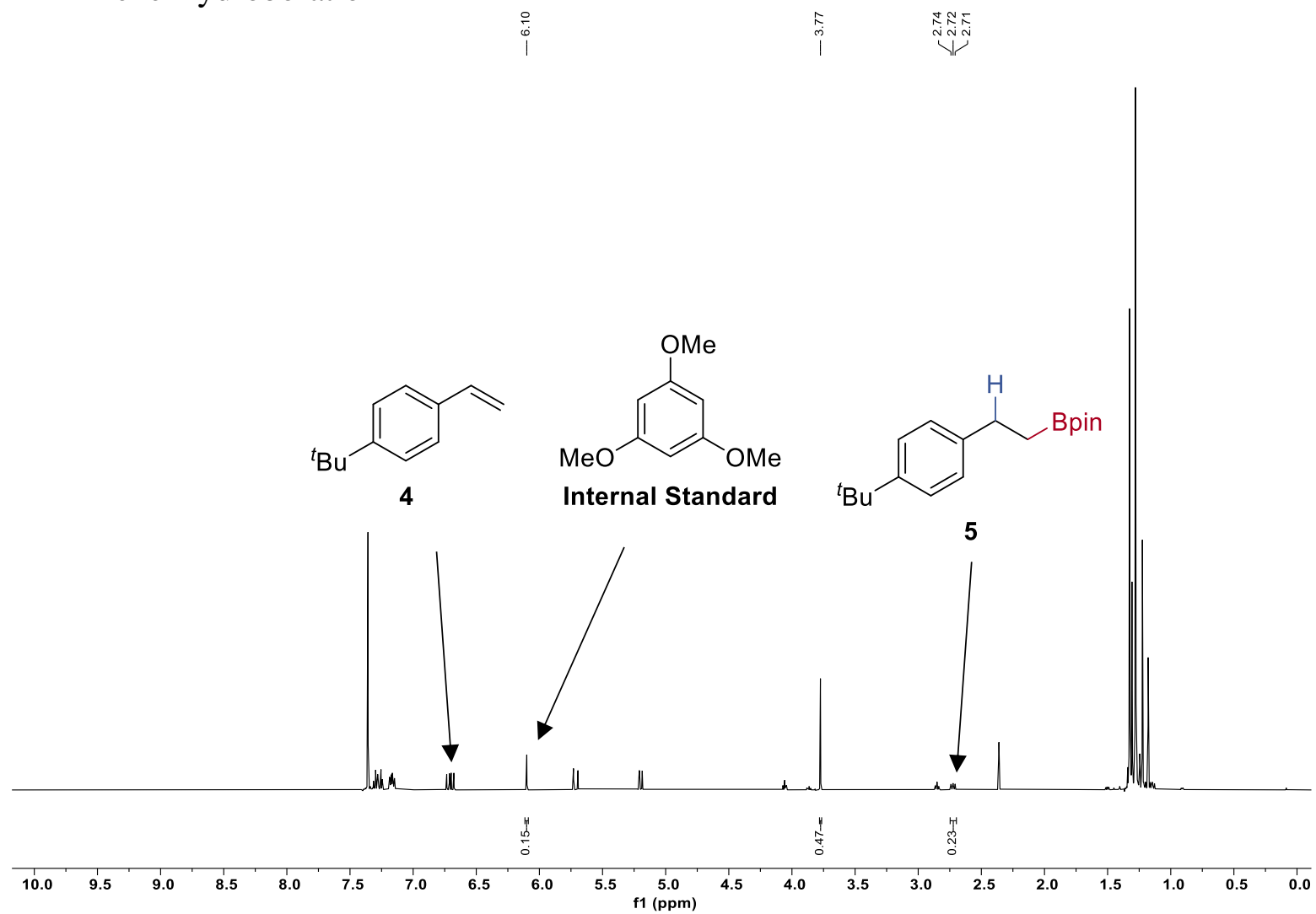

Figure S10. ${ }^{1} \mathrm{H}$ NMR spectrum during turnover, with diagnostic peaks of key species labelled. 
$\mathrm{BH}_{3}$-catalyzed Hydroboration

$$
1 \text { or } 4+\mathrm{H} \text {-Bpin } \frac{\begin{array}{l}
\mathrm{H}_{3} \mathrm{~B} \cdot \mathrm{SMe}_{2} \\
(\mathrm{x} \mathrm{mol})
\end{array}}{60^{\circ} \mathrm{C}, \mathrm{Ar} \text { atm. }} \begin{array}{r}
\mathbf{2} \quad \mathrm{R}=\mathrm{Ph} \\
5 \quad \mathrm{R}=p-\mathrm{C}_{6} \mathrm{H}_{4}{ }^{t} \mathrm{Bu}
\end{array}
$$

Representative Procedure

A stock solution of 1,3,5-trimethoxybenzene in toluene $(1.0 \mathrm{M})$ was prepared under argon and a portion of this $(0.20 \mathrm{~mL}, 0.20 \mathrm{mmol})$ was added to a reaction vial. Toluene $(0.20 \mathrm{~mL})$ and HBpin $(0.44 \mathrm{~mL}, 3.0 \mathrm{mmol})$ were added to the reaction vial, followed by the substrate (phenylacetylene 1 or tert-butylstyrene 4) $(2.0 \mathrm{mmol}) . \mathrm{H}_{3} \mathrm{~B} \cdot \mathrm{SMe}_{2}(10.2 \mathrm{M}$, x mol\%) was added to the reaction vial. The reaction was heated to $60{ }^{\circ} \mathrm{C}$ with stirring, and aliquots were taken at given time intervals, quenching in $\mathrm{Et}_{2} \mathrm{O} .{ }^{1} \mathrm{H} \mathrm{NMR}$ spectra of the aliquots were recorded in $\mathrm{CDCl}_{3}$. A minimum of two runs for each catalyst loading were used to determine average yields. The rate of reaction at the first time point was used as the initial rate of reaction $\left(v_{0}\right)$.

Alkyne Hydroboration
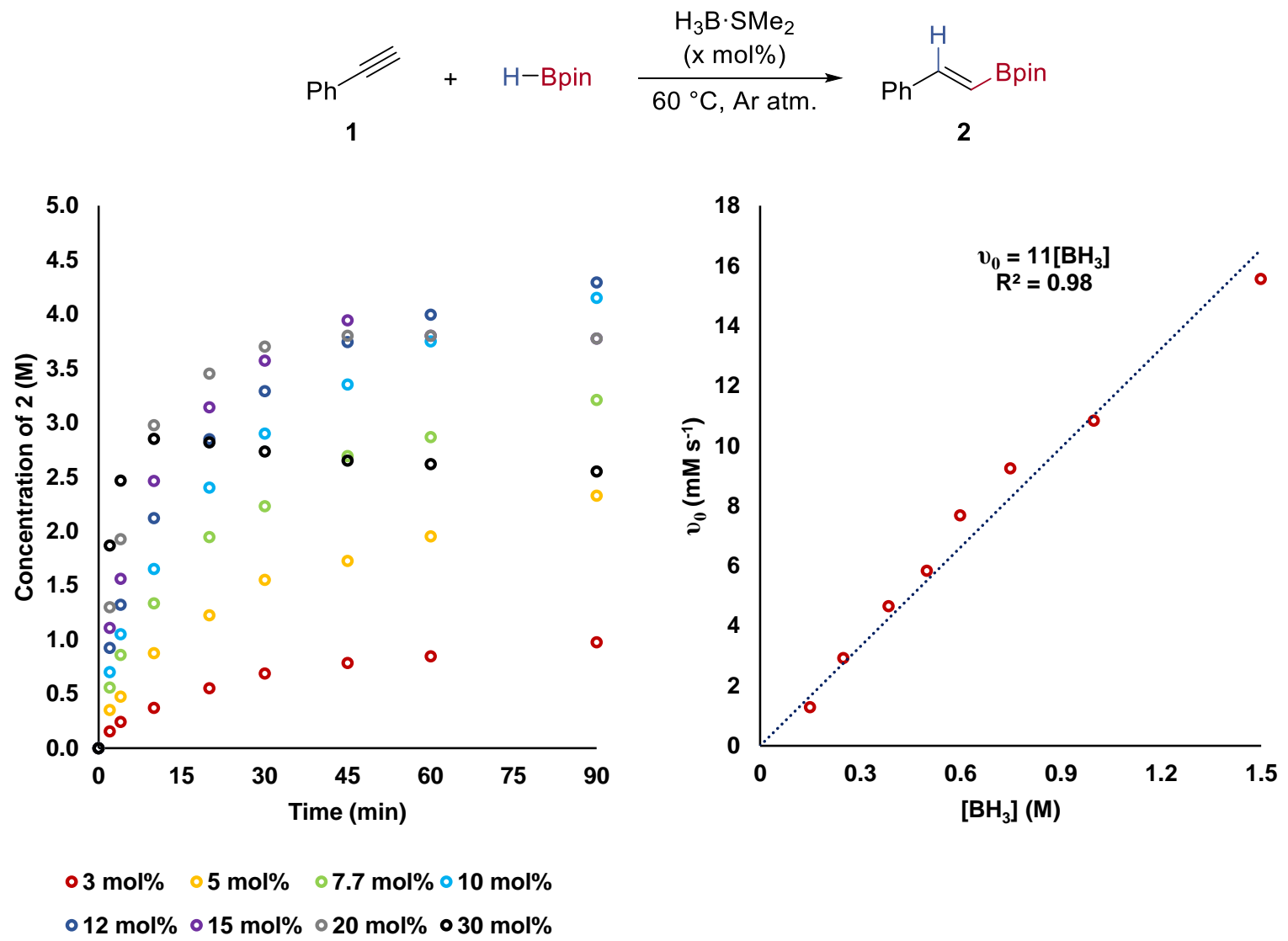

Figure S11. Left - Kinetic profiles for varied $\mathrm{BH}_{3}$ loadings; Right - Calibration gradient of initial Rate of reaction $\left(v_{0}\right)$ plotted against $\mathrm{BH}_{3}$ concentration. 
Alkene Hydroboration
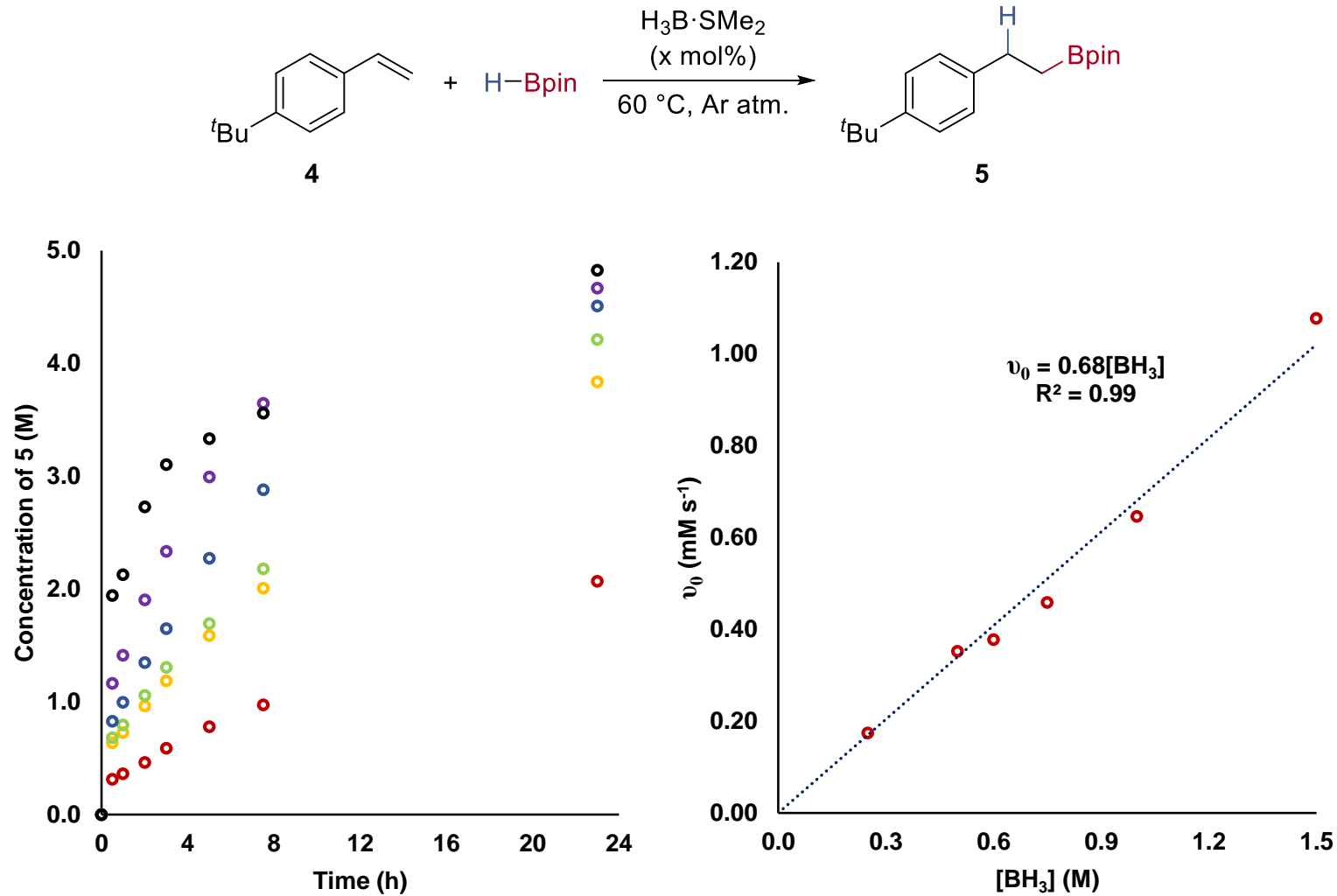

$\circ 5 \mathrm{~mol} \% \circ 10 \mathrm{~mol} \% \circ 12 \mathrm{~mol} \%$

- $15 \mathrm{~mol} \%$ ○ $20 \mathrm{~mol} \%$ ○ $30 \mathrm{~mol} \%$

Figure S12. Left - Kinetic profiles for varied $\mathrm{BH}_{3}$ loadings; Right - Calibration gradient of initial Rate of reaction $\left(v_{0}\right)$ plotted against $\mathrm{BH}_{3}$ concentration. 
Nucleophile-Promoted Hydroboration

$$
\begin{aligned}
& 1 \text { or } 4+\mathrm{H} \text {-Bpin } \frac{\begin{array}{c}
\text { Nucleophile } \\
(10 \mathrm{~mol} \%)
\end{array}}{60^{\circ} \mathrm{C}, \mathrm{Ar} \mathrm{atm} .} \underset{\mathrm{R}}{\longrightarrow} \stackrel{\mathrm{H} \text { Bin }}{\mathrm{H}} \\
& 2 \mathrm{R}=\mathrm{Ph} \\
& 5 \mathrm{R}=p-\mathrm{C}_{6} \mathrm{H}_{4}{ }^{t} \mathrm{Bu}
\end{aligned}
$$

For solid nucleophiles $\left(\mathrm{NaO}^{t} \mathrm{Bu}, \mathrm{Na}\left[\mathrm{N}\left(\mathrm{SiMe}_{3}\right)_{2}\right]\right.$, $\left.\mathrm{LiAlH}_{4}\right)$ :

A stock solution of 1,3,5-trimethoxybenzene in toluene $(1.0 \mathrm{M})$ was prepared under argon and a portion of this $(0.20 \mathrm{~mL}, 0.20 \mathrm{mmol})$ was added to a reaction vial containing the nucleophile $(0.20$ mmol). Toluene $(0.20 \mathrm{~mL})$ and HBpin $(0.44 \mathrm{~mL}, 3.0 \mathrm{mmol})$ were added to the reaction vial, followed by dimethyl sulfide $(15 \mu \mathrm{L}, 0.20 \mathrm{mmol})$. The reaction was heated to $60^{\circ} \mathrm{C}$ for 20 minutes with stirring, followed by the substrate (phenylacetylene 1 or tert-butylstyrene 4) (2.0 mmol). Aliquots were taken at given time intervals, quenching in $\mathrm{Et}_{2} \mathrm{O} .{ }^{1} \mathrm{H}$ NMR spectra of the aliquots were recorded in $\mathrm{CDCl}_{3}$. A minimum of two runs for each catalyst loading were used to determine average yields. The rate of reaction at the first time point was used as the initial rate of reaction $\left(v_{0}\right)$.

For solution-based nucleophiles $\left({ }^{n} \mathrm{BuLi}\right.$ and $\left.{ }^{n} \mathrm{Bu}_{2} \mathrm{Mg}\right)$ :

A stock solution of 1,3,5-trimethoxybenzene in toluene $(1.0 \mathrm{M})$ was prepared under argon and a portion of this $(0.20 \mathrm{~mL}, 0.20 \mathrm{mmol})$ was added to a reaction vial. HBpin $(0.44 \mathrm{~mL}, 3.0 \mathrm{mmol})$ was added to the reaction vial, followed by dimethyl sulfide $(15 \mu \mathrm{L}, 0.20 \mathrm{mmol})$ and the nucleophile $(1.0$ $\mathrm{M}$ in toluene, $0.20 \mathrm{~mL}, 0.20 \mathrm{mmol}$ ). The reaction was heated to $60{ }^{\circ} \mathrm{C}$ for 20 minutes with stirring, followed by the substrate (phenylacetylene 1 or tert-butylstyrene 4) (2.0 mmol). Aliquots were taken at given time intervals, quenching in $\mathrm{Et}_{2} \mathrm{O} .{ }^{1} \mathrm{H}$ NMR spectra of the aliquots were recorded in $\mathrm{CDCl}_{3}$. A minimum of two runs for each catalyst loading were used to determine average yields. The rate of reaction at the first time point was used as the initial rate of reaction $\left(v_{0}\right)$. 
Kinetic Profiles

Table S4. Kinetic profiles for the nucleophile-mediated hydroboration of phenylacetylene $\mathbf{1}$ and tertbutylstyrene 4

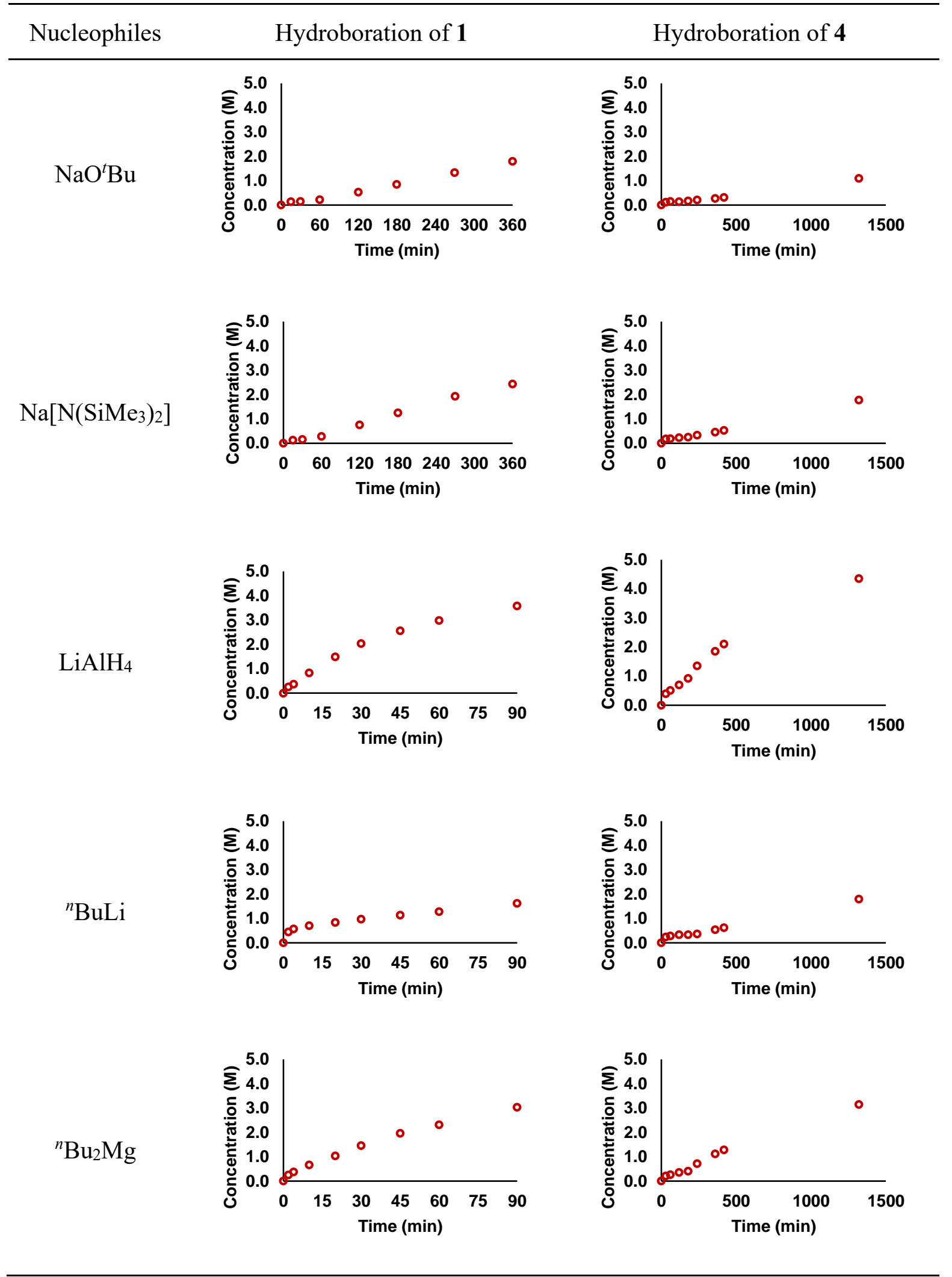


Calculated $\mathrm{BH}_{3}$ Concentrations

Table S5. Rate of Nucleophile-Mediated Phenylacetylene 1 Hydroboration and Comparison to the $\mathrm{BH}_{3}$-catalyzed Reaction

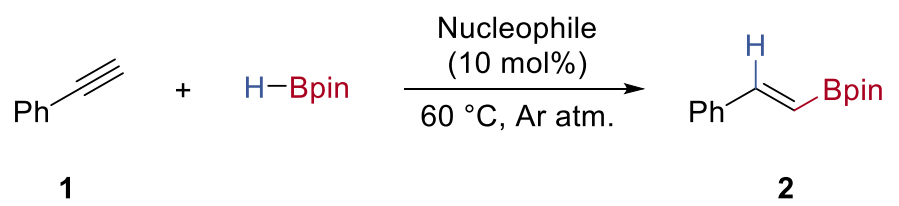

\begin{tabular}{ccc}
\hline Nucleophile & $v_{0}\left(\mathrm{mM} \mathrm{s}^{-1}\right)$ & {$\left[\mathrm{BH}_{3}\right]_{\text {calc }}(\mathrm{M})$} \\
\hline $\mathrm{NaO}^{t} \mathrm{Bu}$ & 0.15 & 0.01 \\
$\mathrm{Na}\left[\mathrm{N}\left(\mathrm{SiMe}_{3}\right)_{2}\right]$ & 0.15 & 0.01 \\
$\mathrm{LiAlH}_{4}$ & 2.1 & 0.19 \\
${ }^{n} \mathrm{Bu}_{2} \mathrm{Mg}$ & 2.0 & 0.18 \\
${ }^{n} \mathrm{BuLi}$ & 3.6 & 0.33 \\
\hline
\end{tabular}

Table S6. Rate of Nucleophile-Mediated tert-Butylstyrene 4 Hydroboration and Comparison to the $\mathrm{BH}_{3}$-catalyzed Reaction

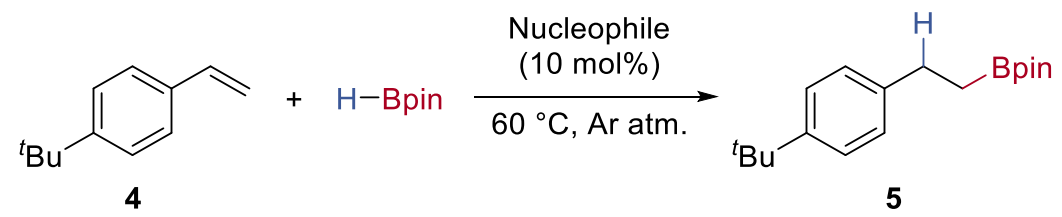

\begin{tabular}{ccc}
\hline Nucleophile & $v_{0}\left(\mathrm{mM} \mathrm{s}^{-1}\right)$ & {$\left[\mathrm{BH}_{3}\right]_{\text {calc }}(\mathrm{M})$} \\
\hline $\mathrm{NaO}{ }^{t} \mathrm{Bu}$ & 0.013 & 0.02 \\
$\mathrm{Na}\left[\mathrm{N}\left(\mathrm{SiMe}_{3}\right)_{2}\right]$ & 0.022 & 0.03 \\
$\mathrm{LiAlH}_{4}$ & 0.22 & 0.32 \\
${ }^{n} \mathrm{Bu}_{2} \mathrm{Mg}$ & 0.11 & 0.16 \\
${ }^{n} \mathrm{BuLi}$ & 0.13 & 0.19
\end{tabular}




\section{Triethylborane-catalyzed Hydroboration}

Triethylborane is commercially available as a solution in hexanes $(1.0 \mathrm{M})$. To make a solution of triethylborane in toluene, triethylborane $(1.0 \mathrm{M}$ in hexanes, $10 \mathrm{~mL}, 10 \mathrm{mmol})$ was dissolved in toluene $(10 \mathrm{~mL})$. The hexanes were removed under reduced pressure to give a $1.2 \mathrm{M}$ solution, determined by ${ }^{11}$ B NMR spectroscopy.

For triethylborane (10 mol\%):

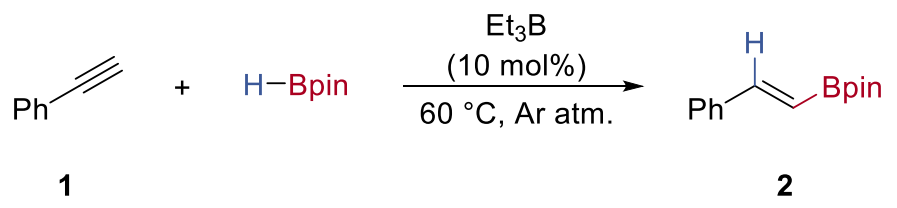

A stock solution of 1,3,5-trimethoxybenzene in toluene $(1.0 \mathrm{M})$ was prepared under argon and a portion of this $(0.20 \mathrm{~mL}, 0.20 \mathrm{mmol})$ was added to a reaction vial. Toluene $(0.03 \mathrm{~mL})$ and $\mathrm{HBpin}$ $(0.44 \mathrm{~mL}, 3.0 \mathrm{mmol})$ were added to the reaction vial, followed by dimethyl sulfide $(15 \mu \mathrm{L}, 0.20$ $\mathrm{mmol})$ and phenylacetylene $1(0.22 \mathrm{~mL}, 2.0 \mathrm{mmol})$. Triethylborane (1.2 $\mathrm{M}$ in toluene, $0.17 \mathrm{~mL}, 0.20$ mmol) was added to the reaction vial. The reaction was heated to $60{ }^{\circ} \mathrm{C}$ with stirring, and aliquots were taken at given time intervals, quenching in $\mathrm{Et}_{2} \mathrm{O} .{ }^{1} \mathrm{H}$ NMR spectra of the aliquots were recorded in $\mathrm{CDCl}_{3}$. Two runs were used to determine average yields. The rate of reaction at the first time point was used as the initial rate of reaction $\left(v_{0}=1.7 \mathrm{mM} \mathrm{s}^{-1}\right)$.

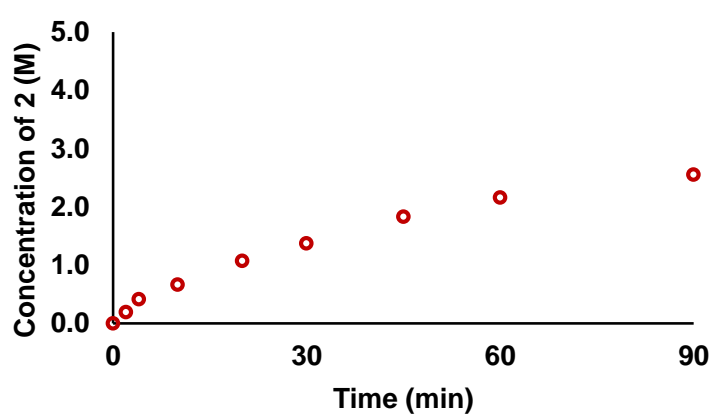

Figure S13. Kinetic profile for the triethylborane-mediated hydroboration of phenylacetylene 1

For ${ }^{n} \mathrm{Bu}_{2} \mathrm{Mg}$ mimic (Triethylborane $1.8 \mathrm{~mol} \%$ and $\mathrm{H}_{3} \mathrm{~B} \cdot \mathrm{SMe}_{2} 1.4 \mathrm{~mol} \%$ ):

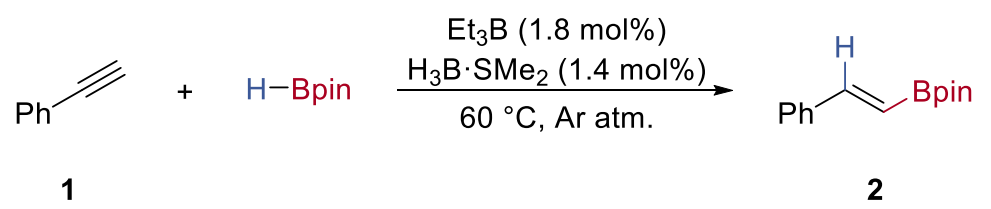

A stock solution of 1,3,5-trimethoxybenzene in toluene $(1.0 \mathrm{M})$ was prepared under argon and a portion of this $(0.20 \mathrm{~mL}, 0.20 \mathrm{mmol})$ was added to a reaction vial. Toluene $(0.20 \mathrm{~mL})$ and HBpin $(0.44 \mathrm{~mL}, 3.0 \mathrm{mmol})$ were added to the reaction vial, followed by dimethyl sulfide $(13 \mu \mathrm{L}, 0.17$ 
mmol) and phenylacetylene $1(0.22 \mathrm{~mL}, 2.0 \mathrm{mmol})$. A stock solution of triethylborane $(1.2 \mathrm{M}$ in toluene, $0.75 \mathrm{~mL}, 0.90 \mathrm{mmol})$ and $\mathrm{H}_{3} \mathrm{~B} \cdot \mathrm{SMe}_{2}(10.2 \mathrm{M}, 69 \mu \mathrm{L}, 0.70 \mathrm{mmol})$ was prepared. A portion of this stock solution $\left(30 \mu \mathrm{L}, \mathrm{Et}_{3} \mathrm{~B} 0.036 \mathrm{mmol}, \mathrm{H}_{3} \mathrm{~B} \cdot \mathrm{SMe}_{2} 0.028 \mathrm{mmol}\right.$ ) was added to the reaction vial. The reaction was heated to $60{ }^{\circ} \mathrm{C}$ with stirring, and aliquots were taken at given time intervals, quenching in $\mathrm{Et}_{2} \mathrm{O}$. ${ }^{1} \mathrm{H}$ NMR spectra of the aliquots were recorded in $\mathrm{CDCl}_{3}$. Two runs were used to determine average yields. The rate of reaction at the first time point was used as the initial rate of reaction $\left(v_{0}=2.0 \mathrm{mM} \mathrm{s}^{-1}\right)$.

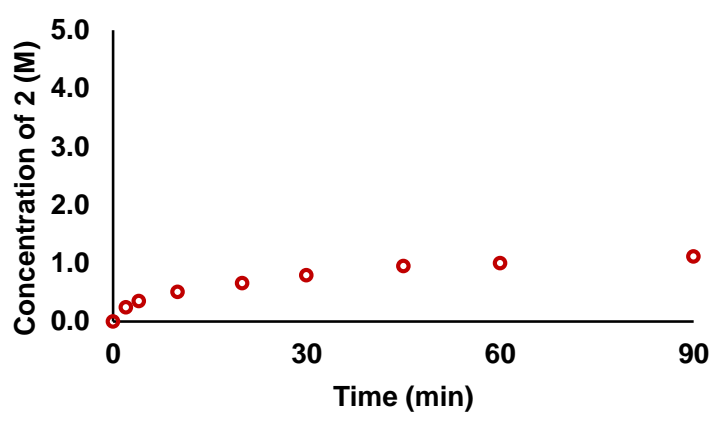

Figure S14. Kinetic profile for the ${ }^{\text {n}} \mathrm{Bu}_{2} \mathrm{Mg}$ mimic'-mediated hydroboration of phenylacetylene $\mathbf{1}$ 
9-BBN-catalyzed Hydroboration

$$
\begin{aligned}
& > \\
& 1 \text { or } 4+\mathrm{H}-\text { Bpin } \underset{6{ }^{\circ} \mathrm{C}, \mathrm{Ar} \mathrm{atm} .}{\stackrel{(10 \mathrm{~mol})}{\longrightarrow}} \\
& 2 \mathrm{R}=\mathrm{Ph} \\
& 5 \quad \mathrm{R}=p-\mathrm{C}_{6} \mathrm{H}_{4}{ }^{t} \mathrm{Bu}
\end{aligned}
$$

A stock solution of 1,3,5-trimethoxybenzene in toluene (1.0 M) was prepared under argon and a portion of this $(0.20 \mathrm{~mL}, 0.20 \mathrm{mmol})$ was added to a reaction vial containing 9borabicyclo[3.3.1]nonane $(24 \mathrm{mg}, 0.20 \mathrm{mmol})$. Toluene $(0.20 \mathrm{~mL})$ and HBpin $(0.44 \mathrm{~mL}, 3.0 \mathrm{mmol})$ were added to the reaction vial, followed by dimethyl sulfide $(15 \mu \mathrm{L}, 0.20 \mathrm{mmol})$. The solution was heated to $60{ }^{\circ} \mathrm{C}$ and the substrate (phenylacetylene 1 or tert-butylstyrene 4) (2.0 mmol) was added with stirring. Aliquots were taken at given time intervals, quenching in $\mathrm{Et}_{2} \mathrm{O}$. ${ }^{1} \mathrm{H} \mathrm{NMR}$ spectra of the aliquots were recorded in $\mathrm{CDCl}_{3}$. A minimum of two runs for each catalyst loading were used to determine average yields. The rate of reaction at the first time point was used as the initial rate of reaction.

Table S7. Kinetic profiles and initial rates of reaction for the 9-BBN-catalyzed hydroboration of phenylacetylene $\mathbf{1}$ and tert-butylstyrene $\mathbf{4}$

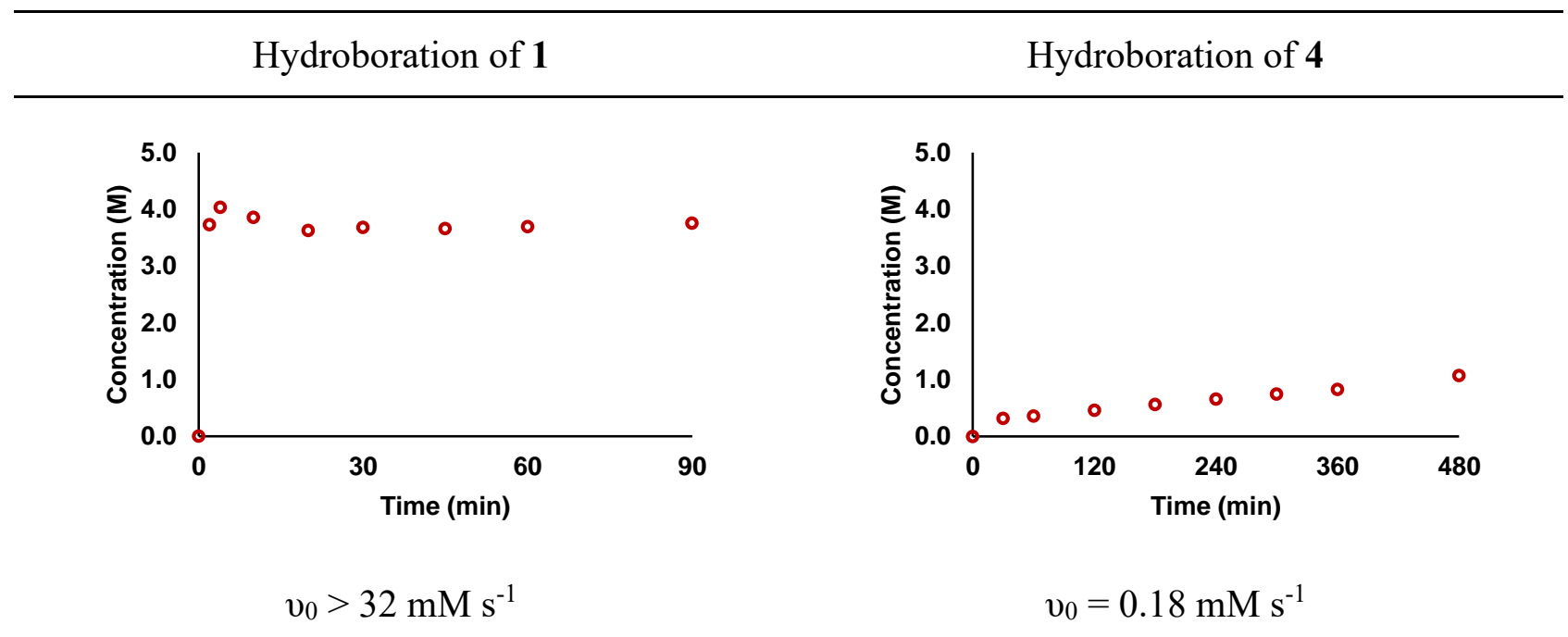

For reference $\mathrm{BH}_{3}(10 \mathrm{~mol} \%): v_{0}=5.8 \mathrm{mM} \mathrm{s}^{-1} \quad$ For reference $\mathrm{BH}_{3}(10 \mathrm{~mol} \%): v_{0}=0.35 \mathrm{mM} \mathrm{s}^{-1}$ 


\section{NMR Spectra}

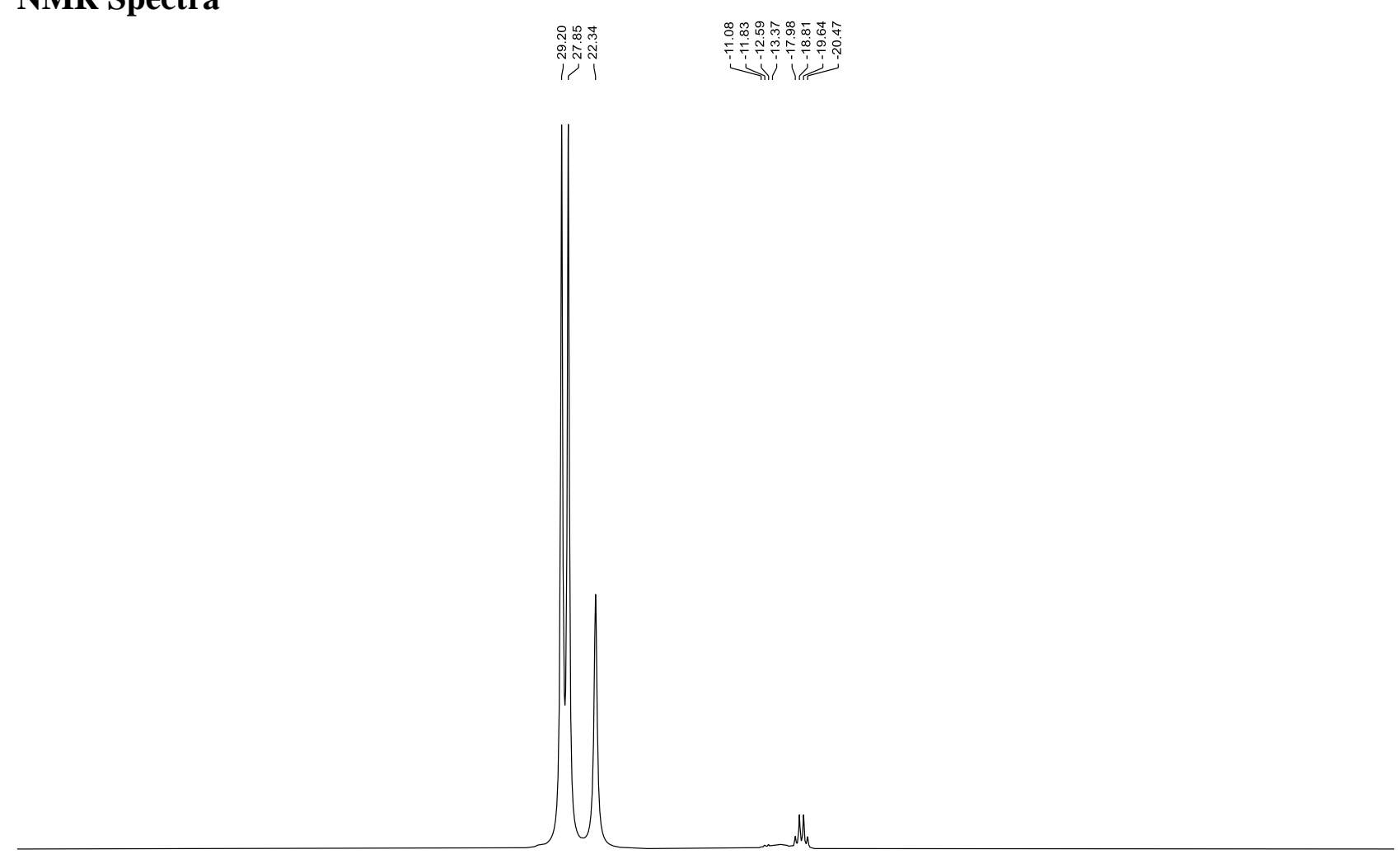

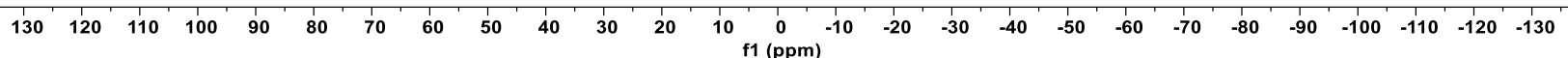

${ }^{11} \mathrm{~B}$ NMR $\left(128 \mathrm{MHz}, h_{8}\right.$-toluene) of the reaction between $\mathrm{Ti}\left(\mathrm{O}^{i} \mathrm{Pr}\right)_{4}$ and $\mathrm{HBpin}$<smiles></smiles>

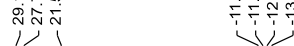

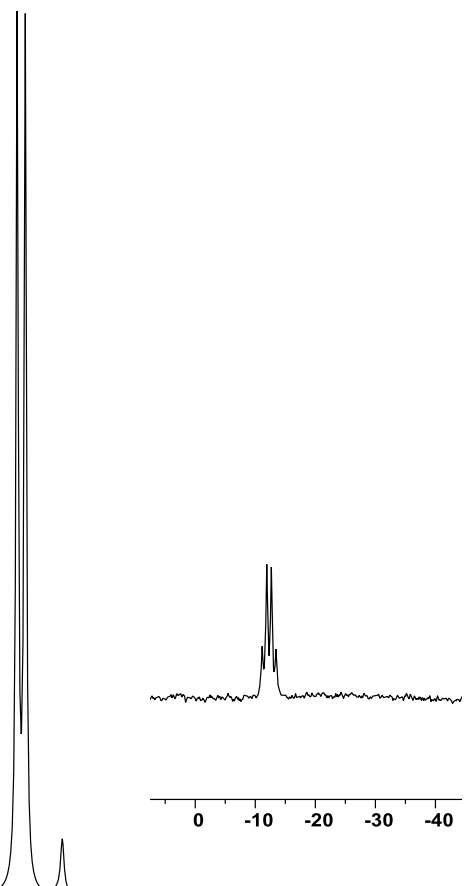

$\begin{array}{lllllllllllllllllllllllllllll}130 & 120 & 110 & 100 & 90 & 80 & 70 & 60 & 50 & 40 & 30 & 20 & 10 & 0 & -10 & -20 & -30 & -40 & -50 & -60 & -70 & -80 & -90 & -100 & -110 & -120 & -130\end{array}$

${ }^{11} \mathrm{~B}$ NMR (128 MHz, $h_{8}$-toluene) of the reaction between $\mathrm{KO}^{t} \mathrm{Bu}$ and $\mathrm{HBpin}$ 


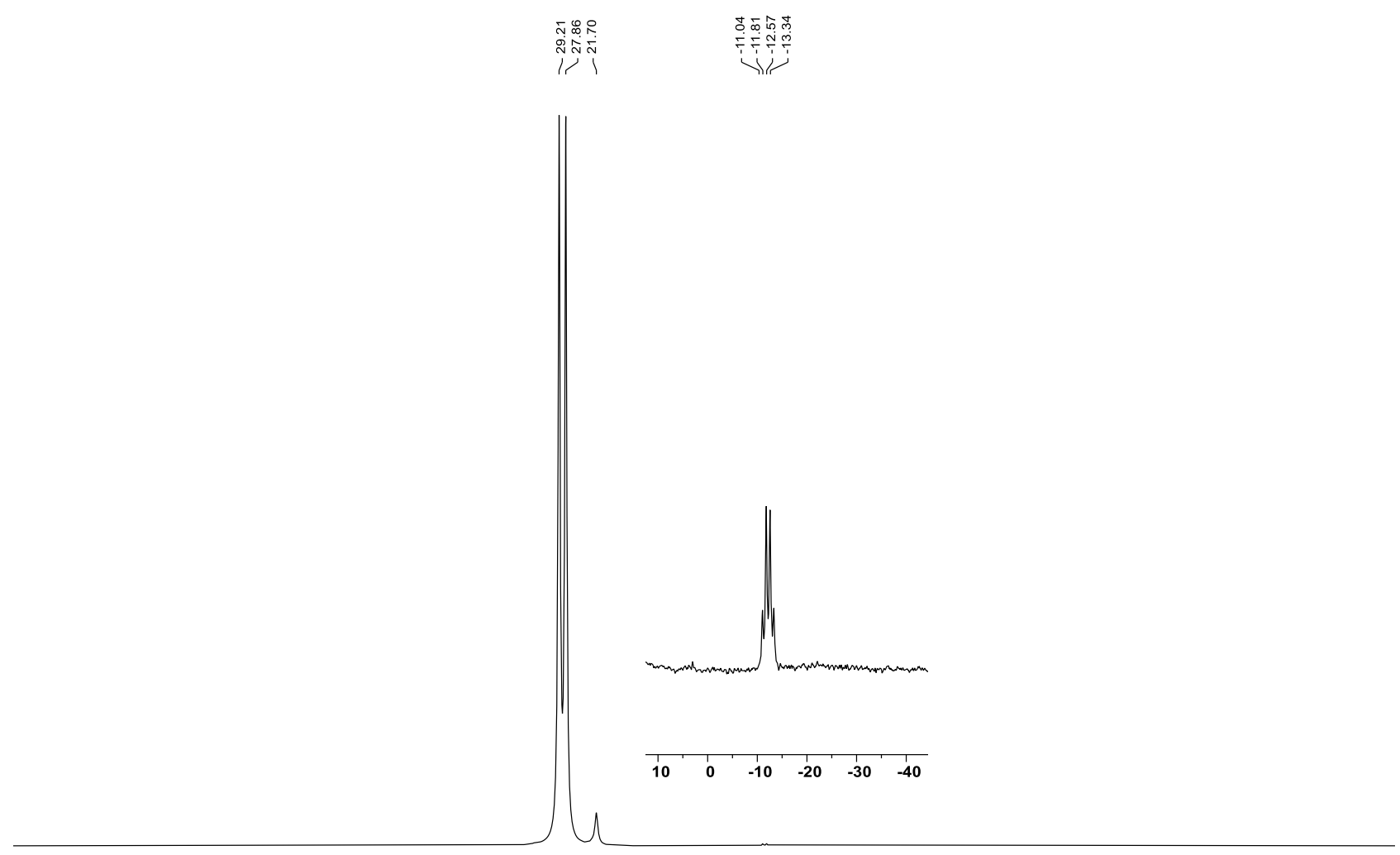

$\begin{array}{llllllllllllllllllllllllllllllllllll}130 & 120 & 110 & 100 & 90 & 80 & 70 & 60 & 50 & 40 & 30 & 20 & 10 & 0 & -10 & -20 & -30 & -40 & -50 & -60 & -70 & -80 & -90 & -100 & -110 & -120 & -130\end{array}$

${ }^{11} \mathrm{~B}$ NMR (128 MHz, $h_{8}$-toluene) of the reaction between $\mathrm{NaO}^{t} \mathrm{Bu}$ and $\mathrm{HB}$ pin

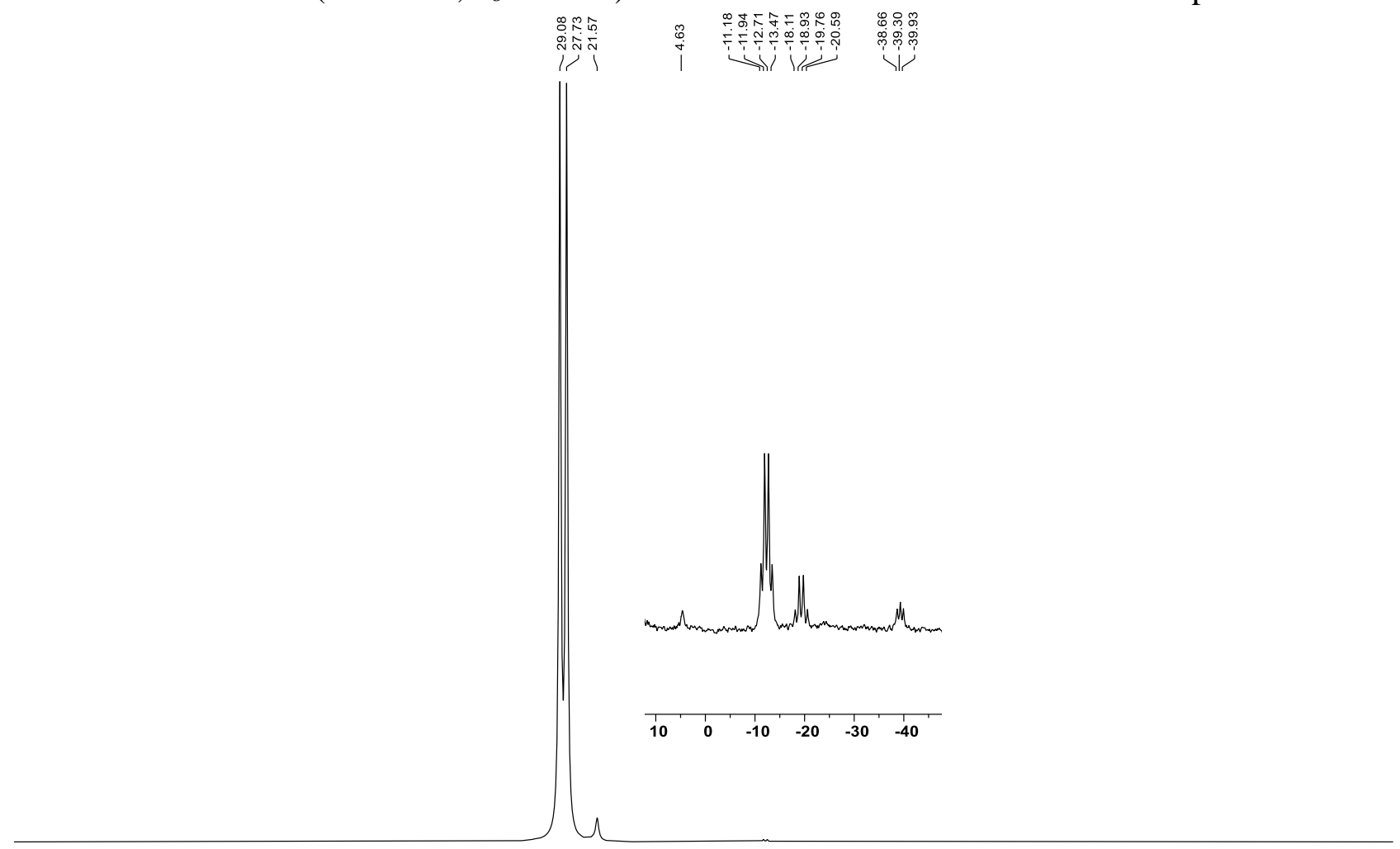

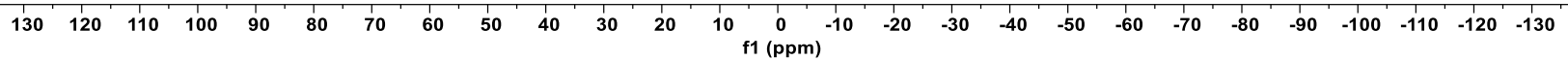

${ }^{11} \mathrm{~B}$ NMR (128 MHz, $h_{8}$-toluene) of the reaction between $\mathrm{LiO}^{t} \mathrm{Bu}$ and $\mathrm{HBpin}$ 

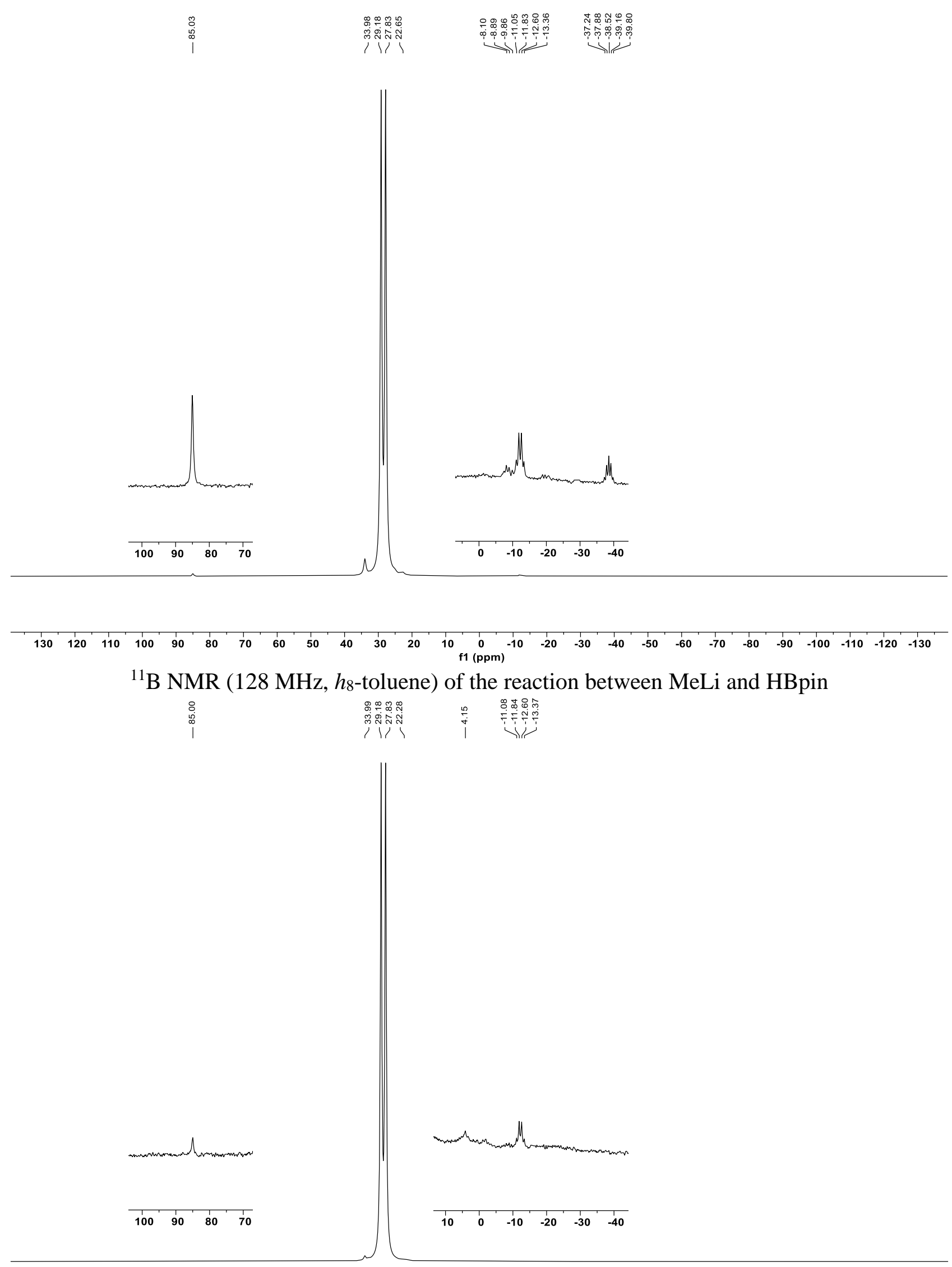

$\begin{array}{llllllllllllllllllllllllllll}130 & 120 & 110 & 100 & 90 & 80 & 70 & 60 & 50 & 40 & 30 & 20 & 10 & 0 & -10 & -20 & -30 & -40 & -50 & -60 & -70 & -80 & -90 & -100 & -110 & -120 & -130 & \end{array}$

${ }^{11} \mathrm{~B}$ NMR (128 MHz, $h_{8}$-toluene) of the reaction between $\mathrm{MeMgBr}$ and $\mathrm{HBpin}$ 

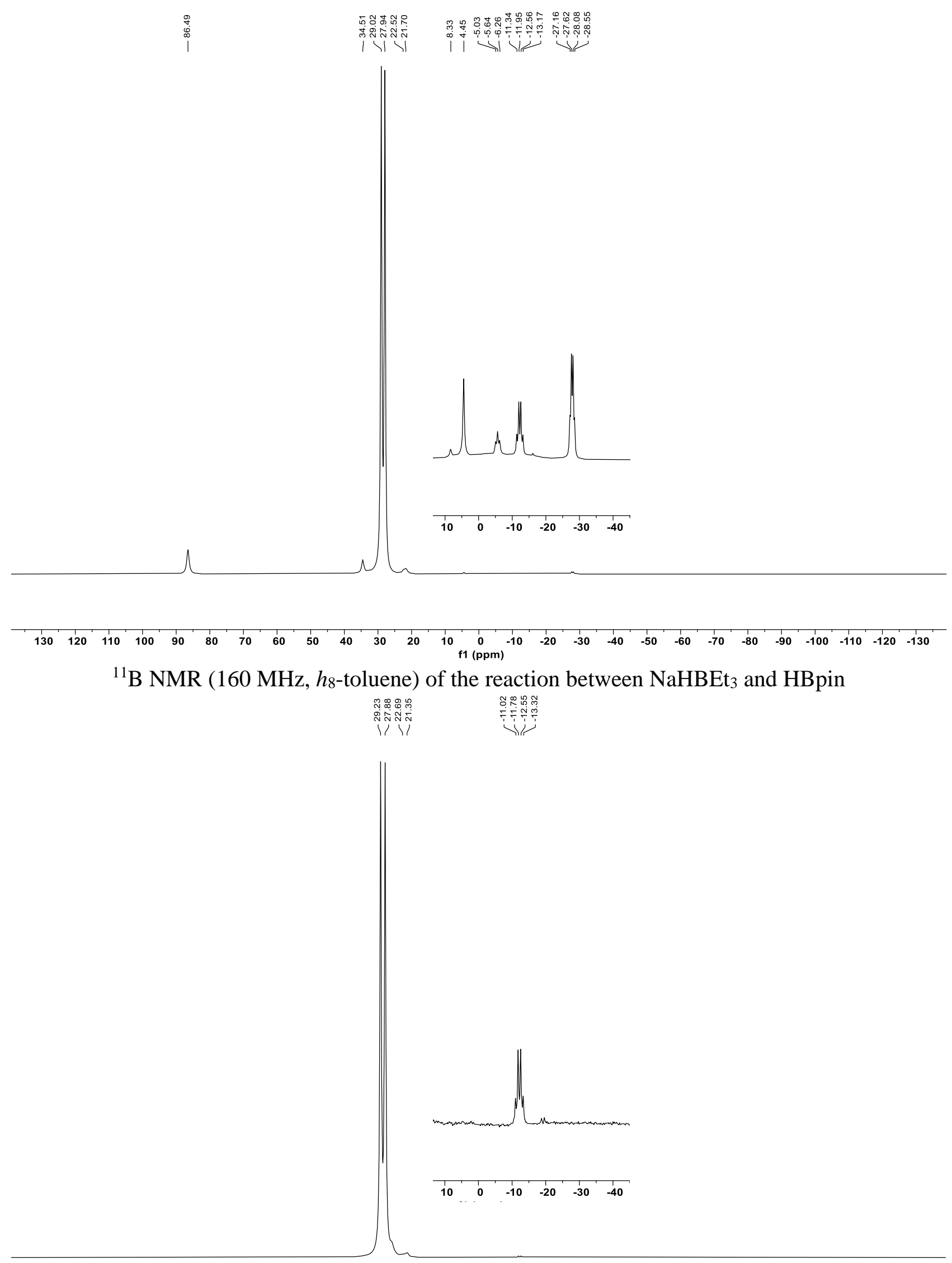

$\begin{array}{lllllllllllllllllllllllllllll}130 & 120 & 110 & 100 & 90 & 80 & 70 & 60 & 50 & 40 & 30 & 20 & 10 & 0 & -10 & -20 & -30 & -40 & -50 & -60 & -70 & -80 & -90 & -100 & -110 & -120 & -130 & \end{array}$

${ }^{11} \mathrm{~B} \mathrm{NMR}\left(128 \mathrm{MHz}, h_{8}\right.$-toluene) of the reaction between $\mathrm{Na}\left[\mathrm{N}\left(\mathrm{SiMe}_{3}\right)_{2}\right]$ and $\mathrm{HBpin}$ 


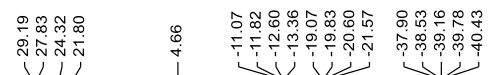

nil
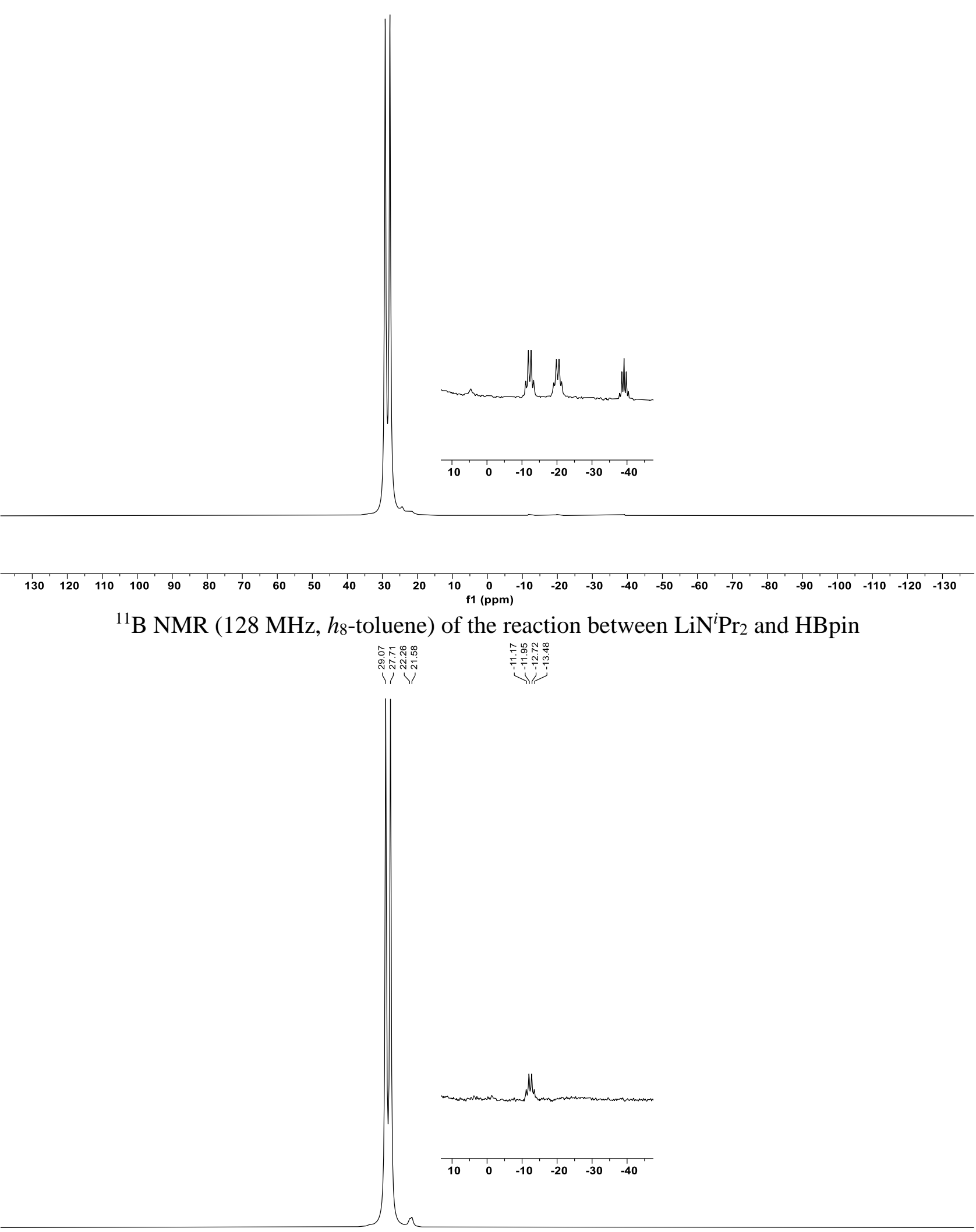

$\begin{array}{lllllllllllllllllllllllllllllllllllllllll}130 & 120 & 110 & 100 & 90 & 80 & 70 & 60 & 50 & 40 & 30 & 20 & 10 & 0 & -10 & -20 & -30 & -40 & -50 & -60 & -70 & -80 & -90 & -100 & -110 & -120 & -130\end{array}$

${ }^{11} \mathrm{~B}$ NMR (128 MHz, $h_{8}$-toluene) of the reaction between $\mathrm{NaOH}$ and HBpin 


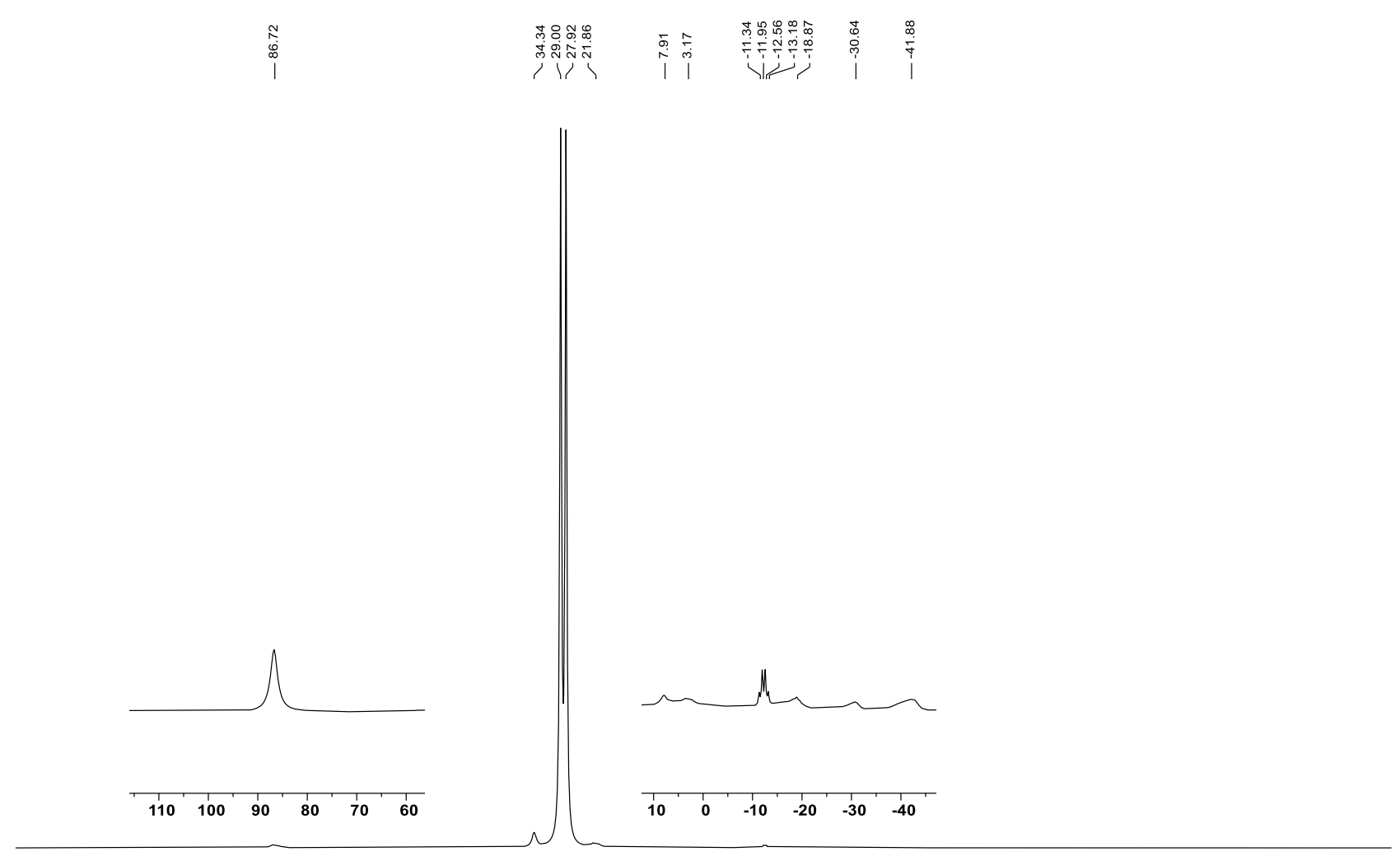

$\begin{array}{lllllllllllllllllllllllllllllllll}130 & 120 & 110 & 100 & 90 & 80 & 70 & 60 & 50 & 40 & 30 & 20 & 10 & 0 & -10 & -20 & -30 & -40 & -50 & -60 & -70 & -80 & -90 & -100 & -110 & -120 & -130\end{array}$

${ }^{11} \mathrm{~B}$ NMR (160 MHz, $h_{8}$-toluene) of the reaction between ${ }^{n} \mathrm{Bu}_{2} \mathrm{Mg}$ and $\mathrm{HBpin}$ $\underset{\substack{\infty \\ 0 \\ 0}}{i}$
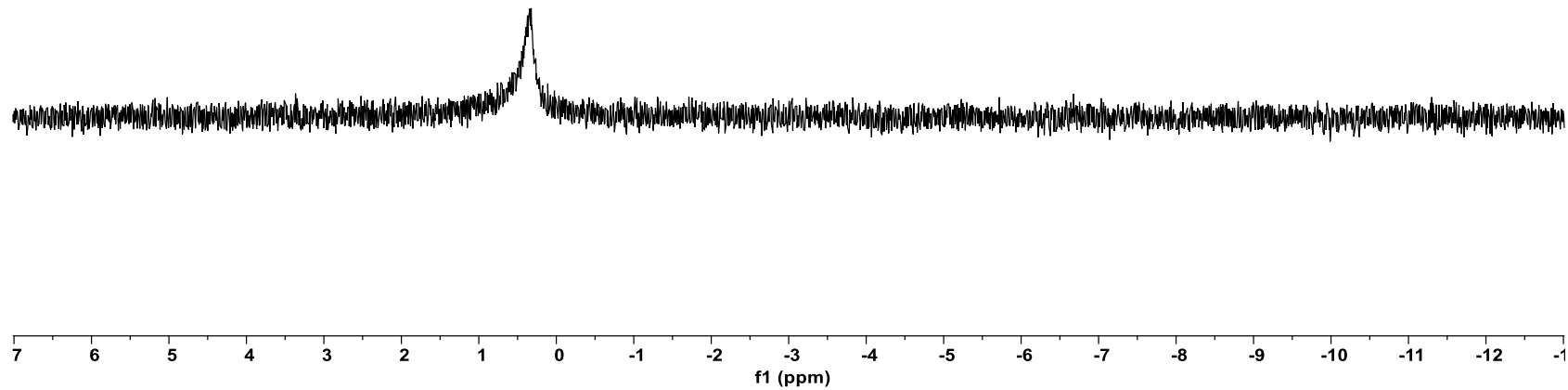

${ }^{7} \mathrm{Li}$ NMR (156 MHz, $h_{8}$-toluene) of the reaction between ${ }^{n} \mathrm{BuLi}$ and HBpin 

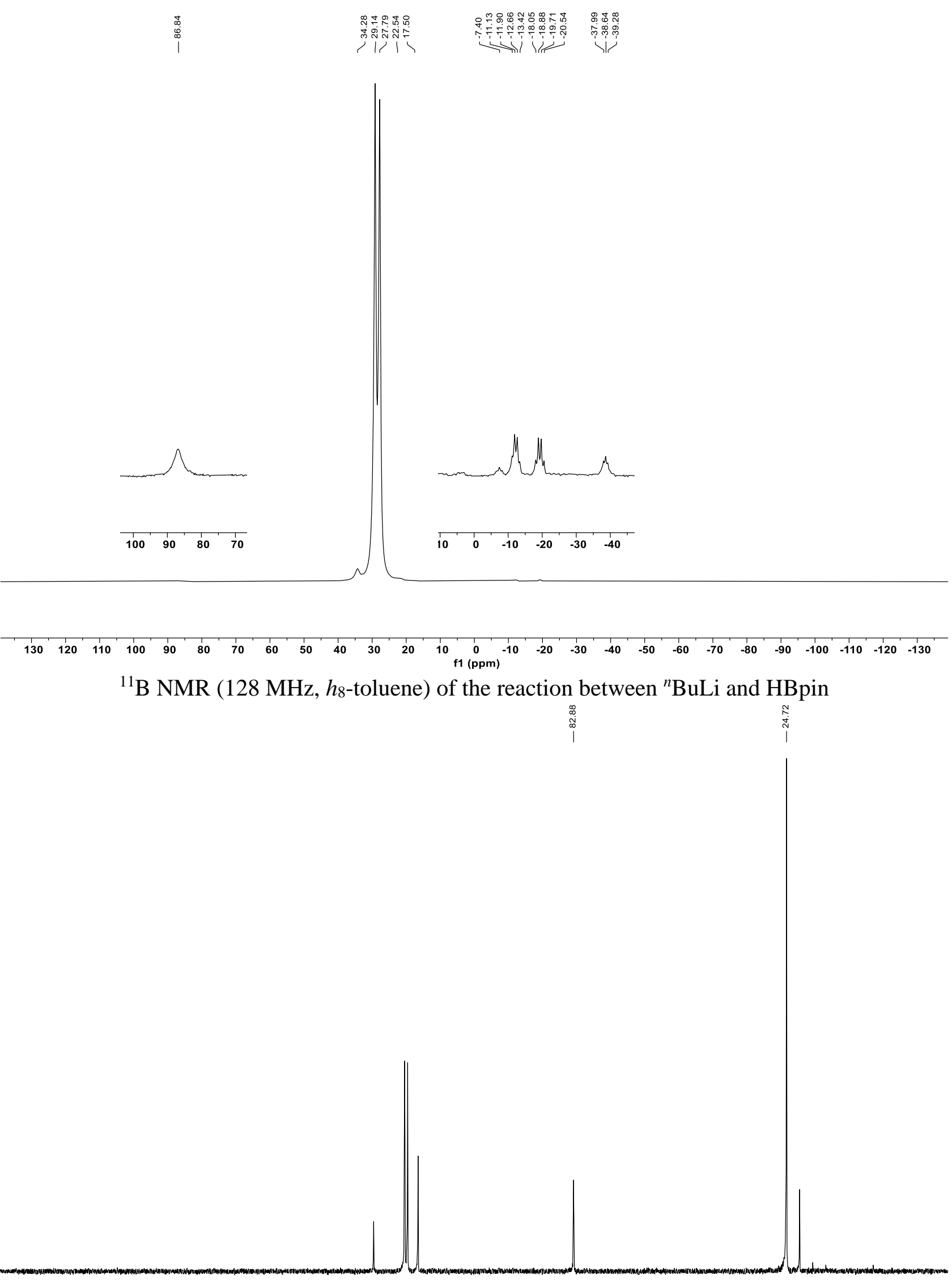

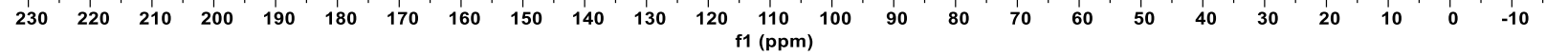

${ }^{13} \mathrm{C}$ NMR (101 MHz, $h_{8}$-toluene) of the reaction between ${ }^{n} \mathrm{BuLi}$ and HBpin 


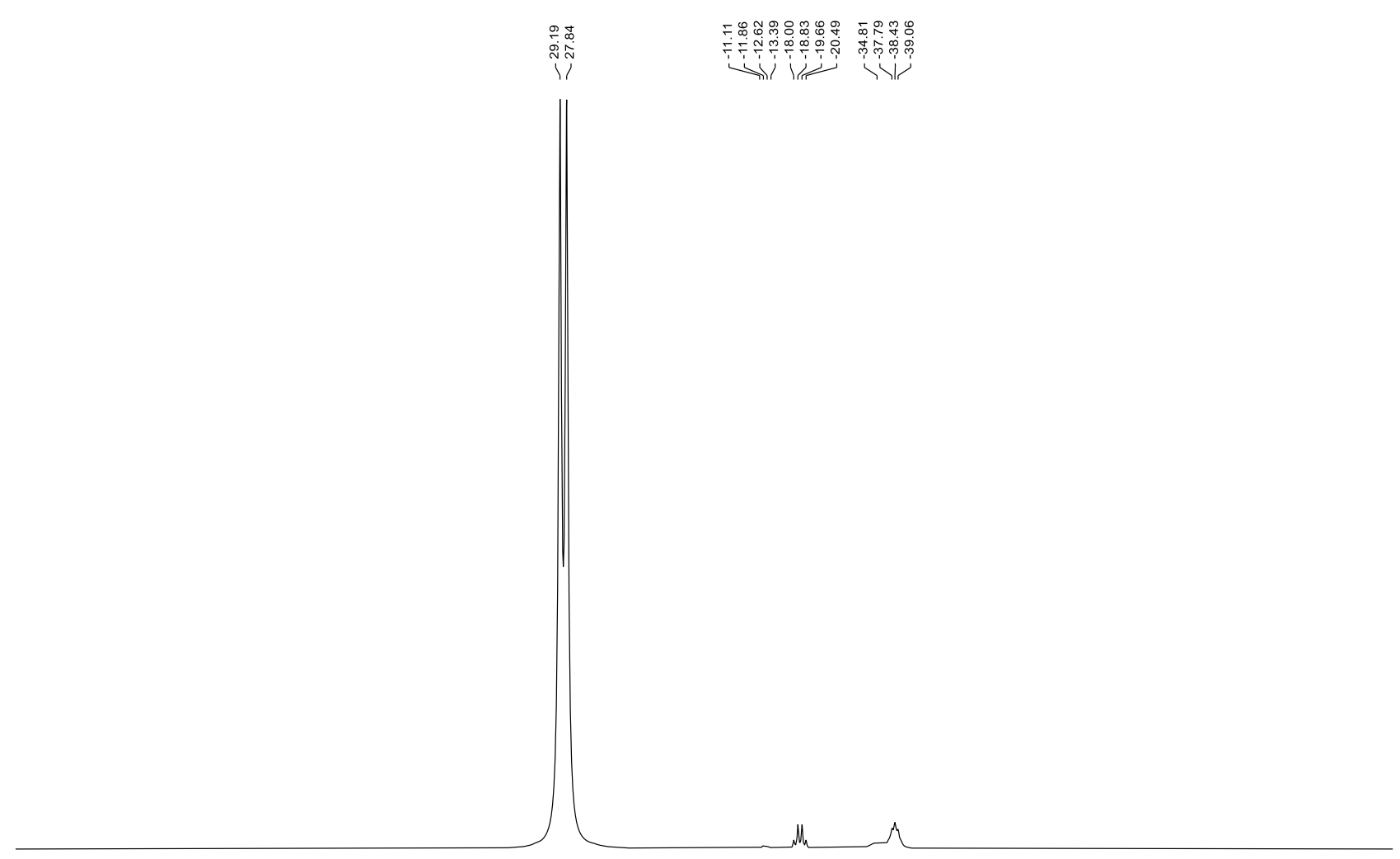

$\begin{array}{lllllllllllllllllllllllllllllllll}130 & 120 & 110 & 100 & 90 & 80 & 70 & 60 & 50 & 40 & 30 & 20 & 10 & 0 & -10 & -20 & -30 & -40 & -50 & -60 & -70 & -80 & -90 & -100 & -110 & -120 & -130\end{array}$

${ }^{11} \mathrm{~B}$ NMR (128 MHz, $h_{8}$-toluene) of the reaction between $\mathrm{LiAlH}_{4}$ and $\mathrm{HBpin}$

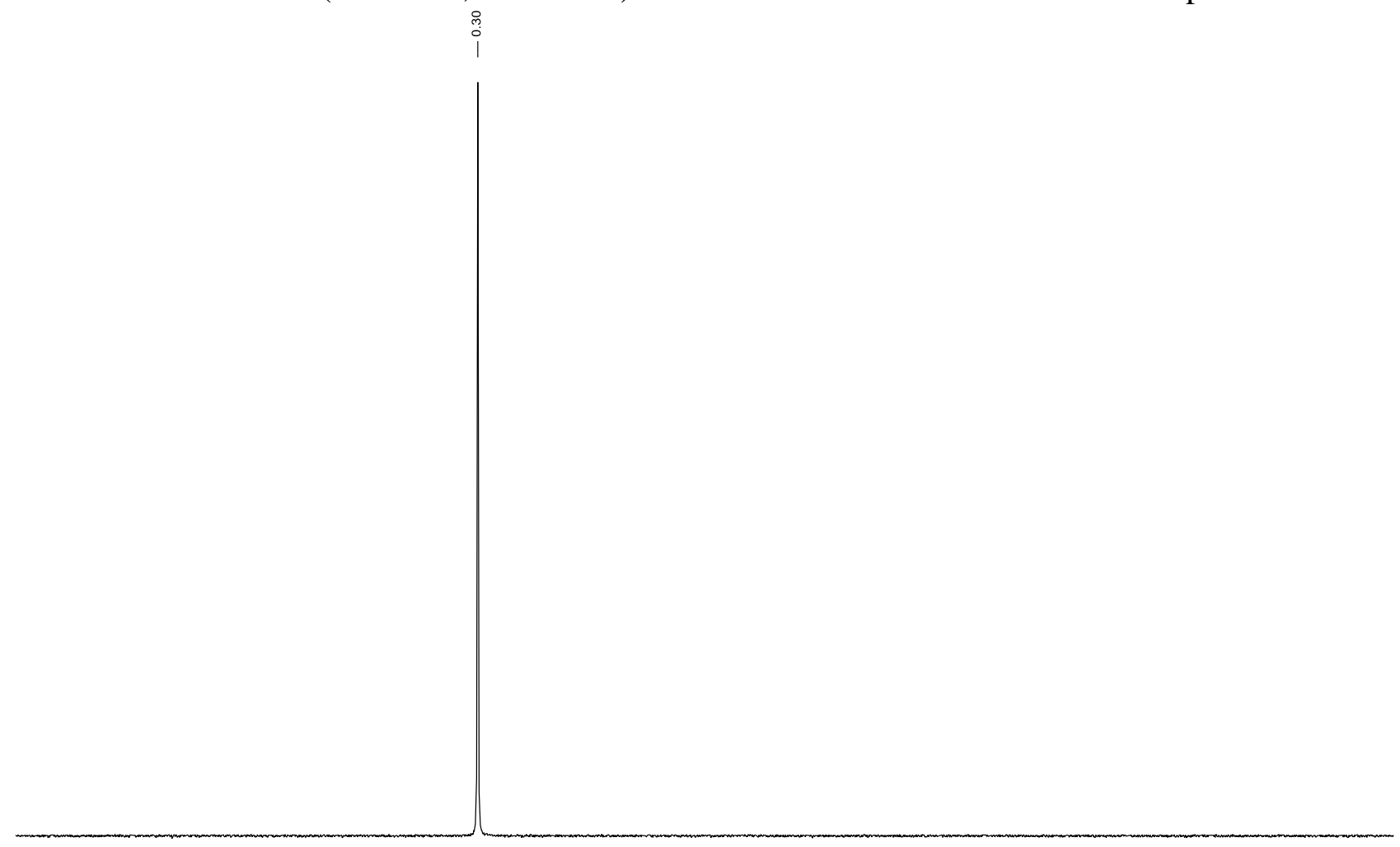

5

${ }^{7} \mathrm{Li}$ NMR (194 MHz, $h_{8}$-toluene) of the reaction between $\mathrm{LiBH}_{4}$ and HBpin 

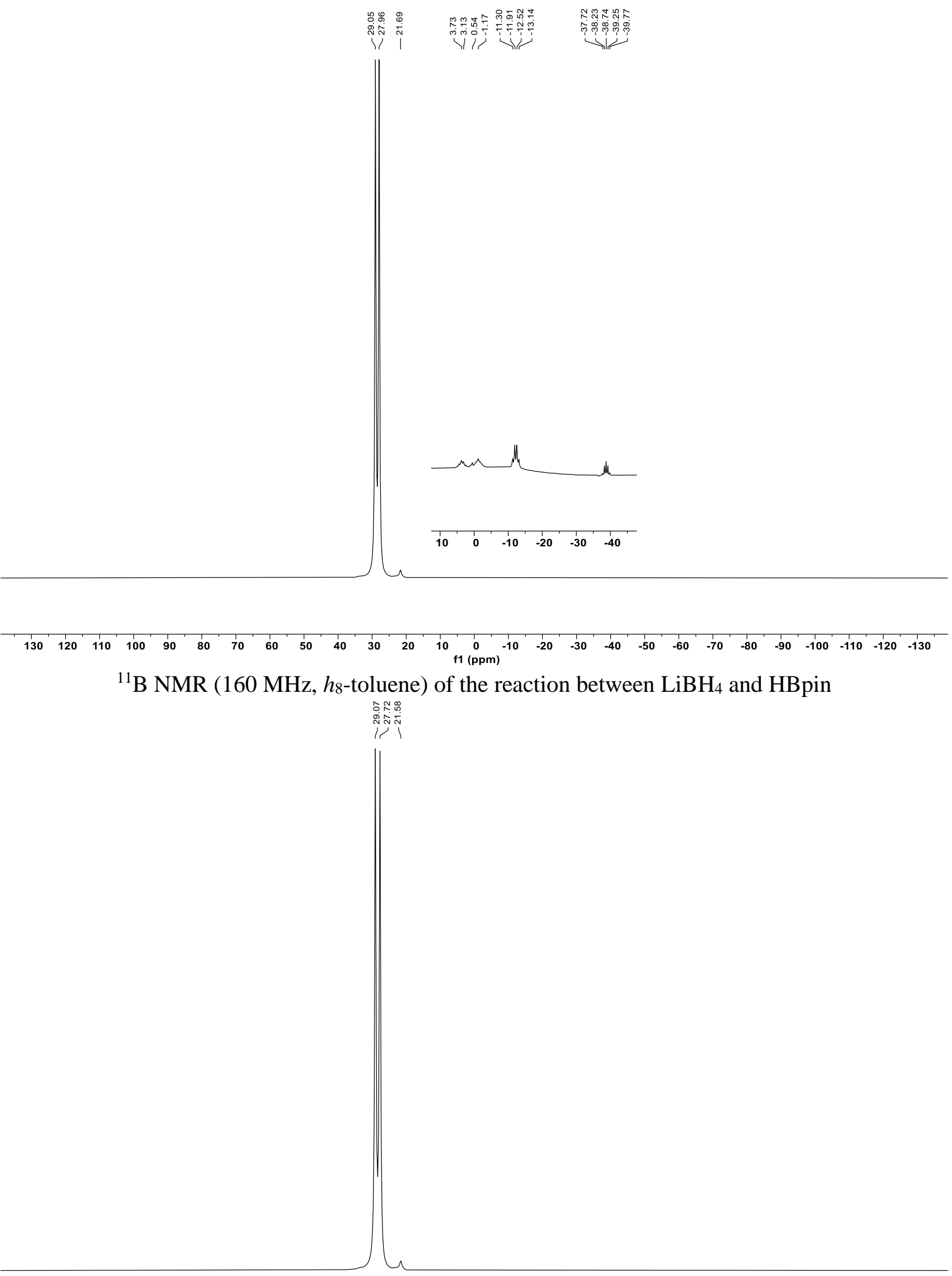

$\begin{array}{llllllllllllllllllllllllllllll}130 & 120 & 110 & 100 & 90 & 80 & 70 & 60 & 50 & 40 & 30 & 20 & 10 & 0 & -10 & -20 & -30 & -40 & -50 & -60 & -70 & -80 & -90 & -100 & -110 & -120 & -130 & \end{array}$

${ }^{11} \mathrm{~B}$ NMR (128 MHz, $h_{8}$-toluene) of the reaction between NaOTf and HBpin 


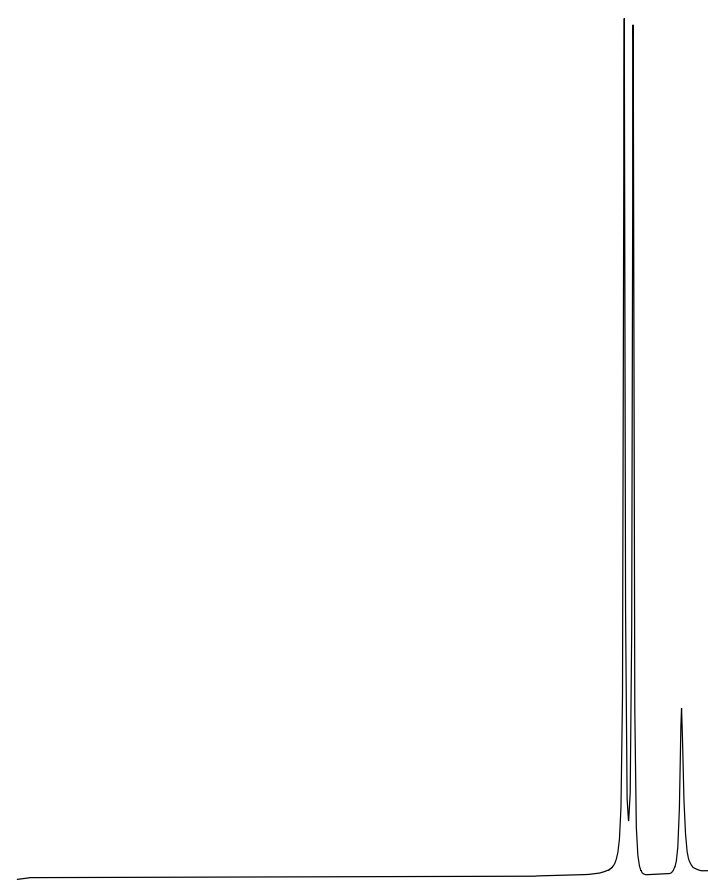

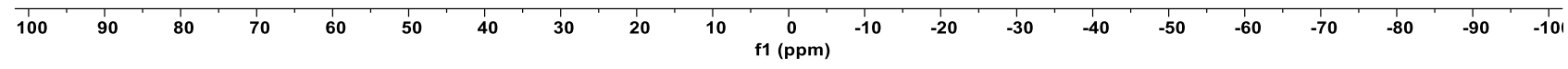

${ }^{11} \mathrm{~B}$ NMR (160 MHz, $h_{8}$-THF) of HBpin and TMEDA

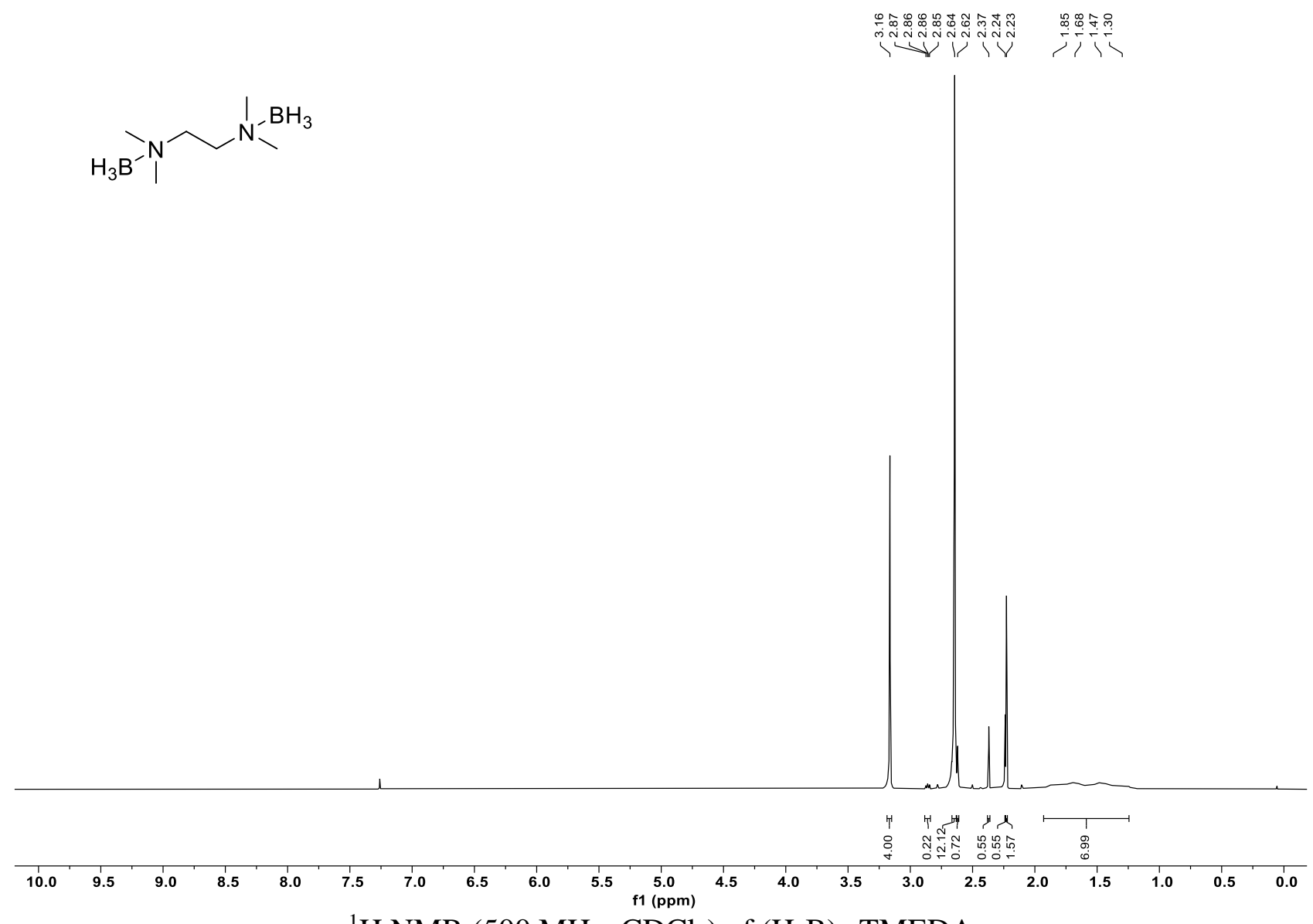

${ }^{1} \mathrm{H}$ NMR $\left(500 \mathrm{MHz}, \mathrm{CDCl}_{3}\right)$ of $\left(\mathrm{H}_{3} \mathrm{~B}\right)_{2} \cdot \mathrm{TMEDA}$ 

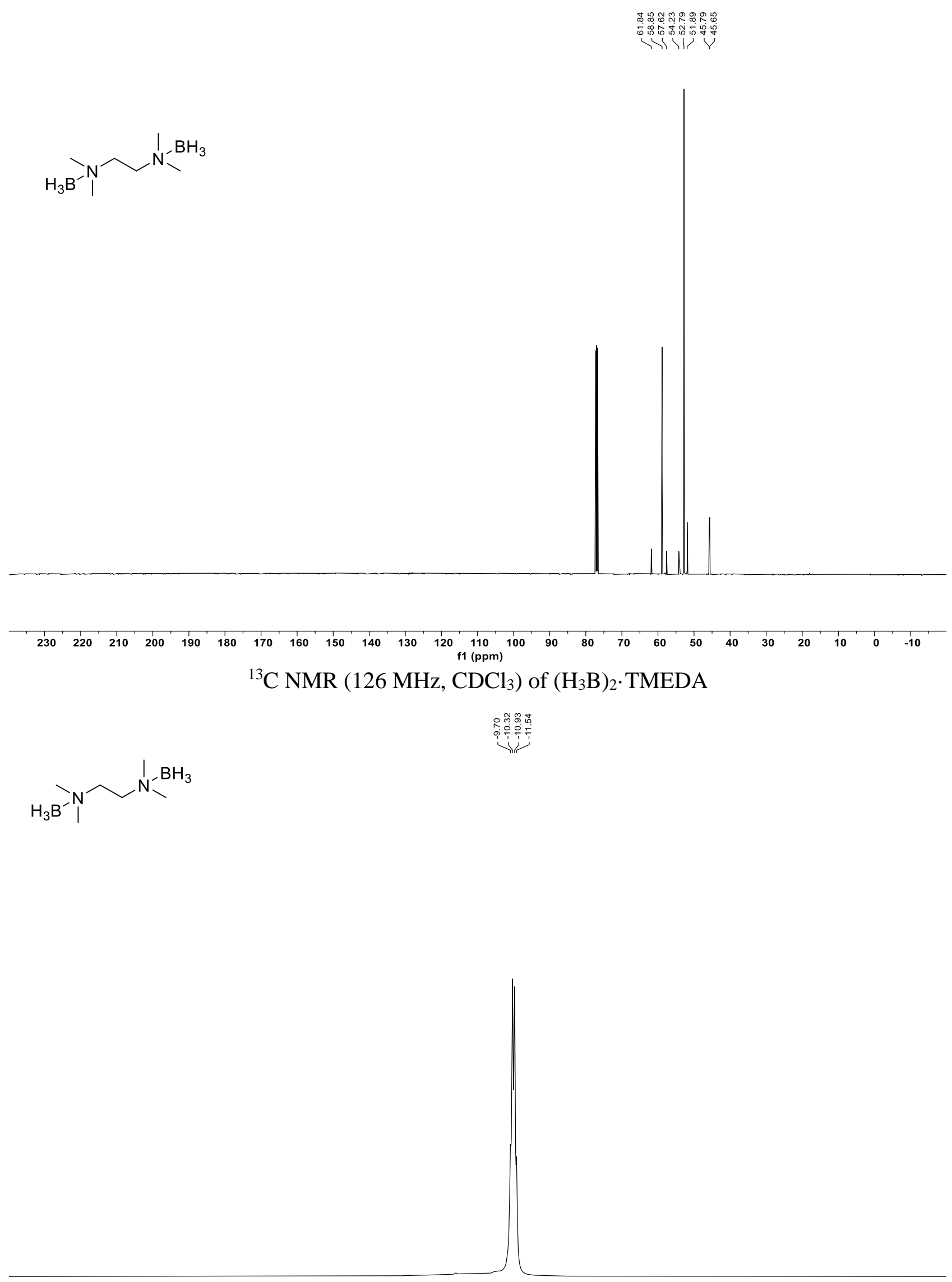

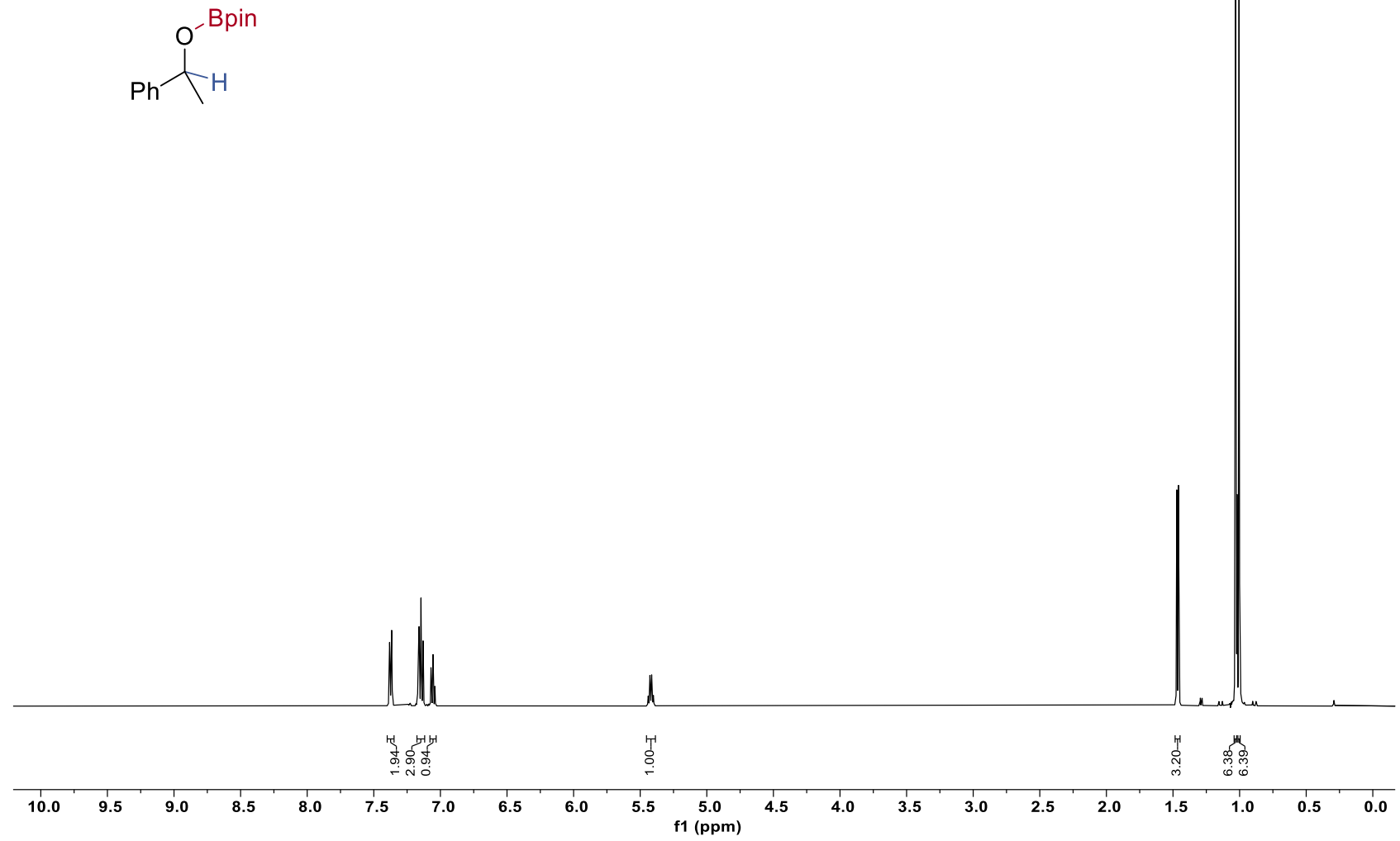

${ }^{1} \mathrm{H}$ NMR (500 MHz, $\mathrm{C}_{6} \mathrm{D}_{6}$ ) of 4,4,5,5-tetramethyl-2-(1-phenylethoxy)-1,3,2-dioxaborolane, $\mathbf{S 1}$

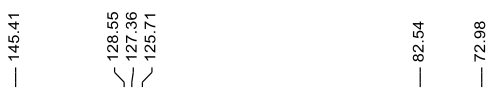

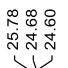

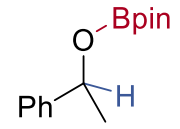

\begin{tabular}{llllllllllllllllllllllllll}
\hline 40 & 230 & 220 & 210 & 200 & 190 & 180 & 170 & 160 & 150 & 140 & 130 & 120 & $\begin{array}{c}110 \\
\mathrm{f} 1(\mathrm{ppm})\end{array}$ & 100 & 90 & 80 & 70 & 60 & 50 & 40 & 30 & 20 & 10 & 0 & -10
\end{tabular}

${ }^{13} \mathrm{C}$ NMR (126 MHz, $\mathrm{C}_{6} \mathrm{D}_{6}$ ) of 4,4,5,5-tetramethyl-2-(1-phenylethoxy)-1,3,2-dioxaborolane, $\mathbf{S 1}$ 


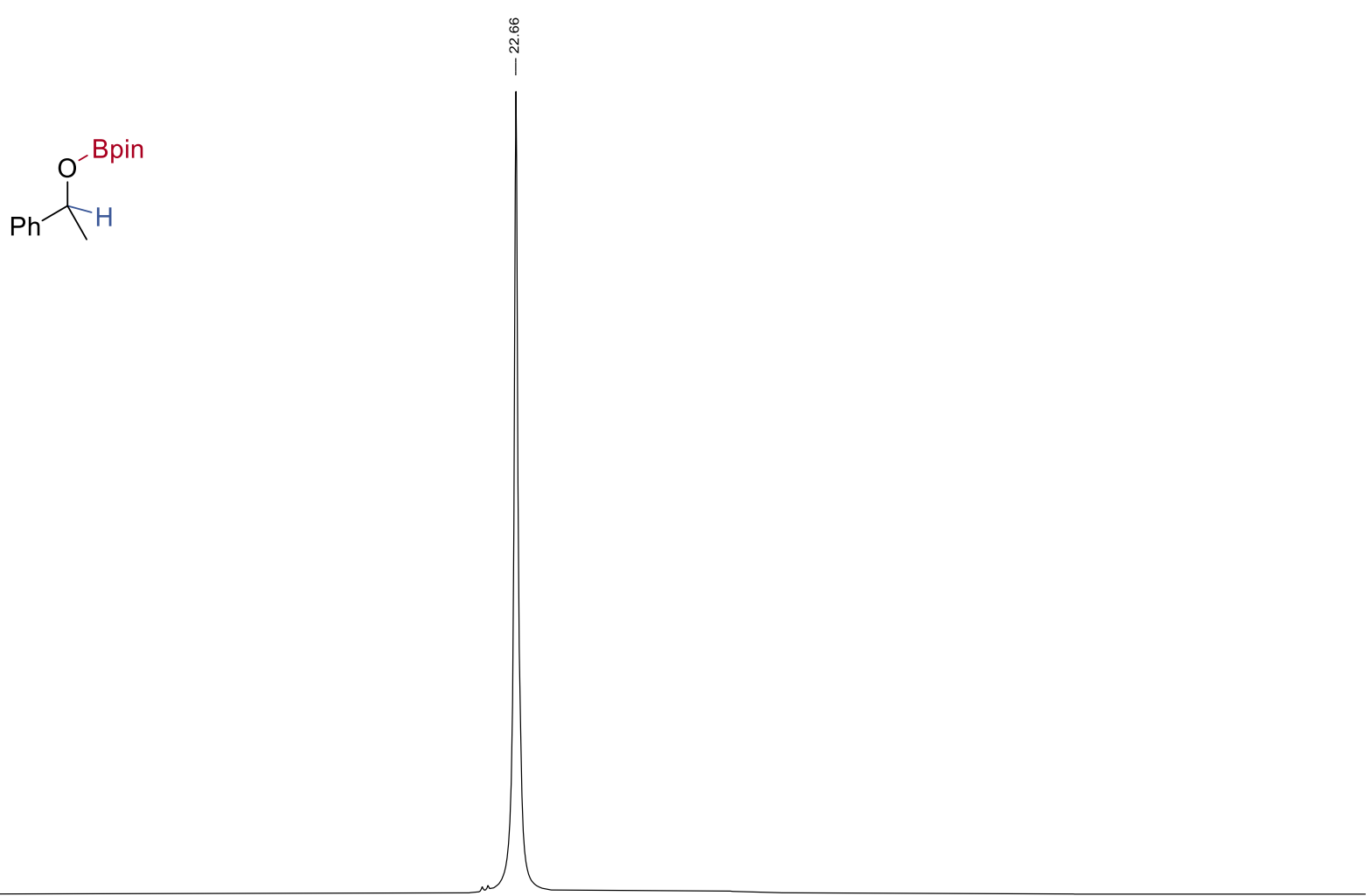

$\begin{array}{llllllllllllllllllllllllllllllllll}130 & 120 & 110 & 100 & 90 & 80 & 70 & 60 & 50 & 40 & 30 & 20 & 10 & 0 & -10 & -20 & -30 & -40 & -50 & -60 & -70 & -80 & -90 & -100 & -110 & -120 & -130\end{array}$

${ }^{11}$ B NMR (160 MHz, $\mathrm{C}_{6} \mathrm{D}_{6}$ ) of 4,4,5,5-tetramethyl-2-(1-phenylethoxy)-1,3,2-dioxaborolane, $\mathbf{S 1}$

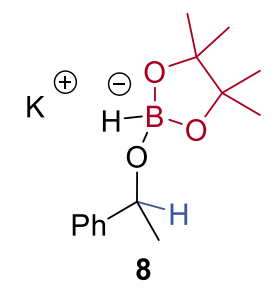

${ }^{11} \mathrm{~B}$ NMR (160 MHz, $h_{8}$-THF) of lithium 4,4,5,5-tetramethyl-2-(1-phenylethoxy)-1,3,2dioxaborolan-2-uide, 8 


\section{References}

(1) Query, I. P.; Squier, P. A.; Larson, E. M.; Isley, N. A.; Clark, T. B. Alkoxide-Catalyzed Reduction of Ketones with Pinacolborane. J. Org. Chem. 2011, 76, 6452-6456.

(2) Gilmore, N. J.; Jones, S. Evaluating the role of solvent and borane on the enantioselectivity of the oxazaborolidine reduction of prochiral ketones using catalysts derived from cis- $(1 R, 2 S)-1$ amino-indan-2-ol. Tetrahedron: Asymmetry 2003, 14, 2115-2118.

(3) Onak, T.; Landesman, H.; Williams, R.; Shapiro, I. The B ${ }^{11}$ Nuclear Magnetic Resonance Chemical Shifts and Spin Coupling Values for Various Compounds. J. Phys. Chem. 1959, 63, 15331535 .

(4) Gaines, D. F. Nuclear Magnetic Resonance Studies of Diborane and Sodium Diborohydride. Inorg. Chem. 1963, 2, 523-526.

(5) Contreras, R.; Wrackmeyer, B. Application of ${ }^{11} \mathrm{~B}$ nuclear magnetic resonance spectroscopy to the study of hydroboration-III. ${ }^{11} \mathrm{~B}$ Nuclear magnetic resonance study of exchange reactions of triorganyl boranes with borane in tetrahydrofuran and dimethyl sulfide. Spectrochim. Acta, Part A 1982, 38, 941-951.

(6) Joannou, M. V.; Moyer, B. S.; Goldfogel, M. J.; Meek, S. J. Silver(I)-Catalyzed Diastereoselective Synthesis of anti-1,2-Hydroxyboronates. Angew. Chem. Int. Ed. 2015, 54, 1414114145.

(7) Gatti, A. R.; Wartik, T. Preparation and Properties of the Monoborane Adduct of $N, N, N^{\prime}, N^{\prime}-$ Tetramethylethylenediamine. Inorg. Chem. 1966, 5, 329-330.

(8) Bugarin, A.; Connell, B. T. Acceleration of the Morita-Baylis-Hillman Reaction by a Simple Mixed Catalyst System. J. Org. Chem. 2009, 74, 4638-4641.

(9) Khoo, S.; Cao, J.; Ng, F.; So, C.-W. Synthesis of a Base-Stabilized Silicon(I)-Iron(II) Complex for Hydroboration of Carbonyl Compounds. Inorg. Chem. 2018, 57, 12452-12455.

(10) Docherty, J. H.; Peng, J.; Dominey, A. P.; Thomas, S. P. Activation and discovery of earthabundant metal catalysts using sodium tert-butoxide. Nature Chem. 2017, 9, 595-600.

(11) Fleige, M.; Mobus, J.; vom Stein, T.; Glorius, F.; Stephan, D. W. Lewis acid catalysis: catalytic hydroboration of alkynes initiated by Piers' borane. Chem. Commun. 2016, 52, 1083010833.

(12) Ang, N. W. J.; Buettner, C. S.; Docherty, S.; Bismuto, A.; Carney, J. R.; Docherty, J. H.; Cowley, M. J.; Thomas, S. P. Borane-Catalysed Hydroboration of Alkynes and Alkenes. Synthesis 2018, 50, 803-808.

(13) Verma, P. K.; A. S, S.; Geetharani, K. Markovnikov-Selective Co(I)-Catalyzed Hydroboration of Vinylarenes and Carbonyl Compounds. Org. Lett. 2018, 20, 7840-7845.

(14) Zhu, K.; Shaver, M. P.; Thomas, S. P. Stable and Easily Handled Fe ${ }^{\text {III }}$ Catalysts for Hydrosilylation of Ketones and Aldehydes. Eur. J. Org. Chem. 2015, 2015, 2119-2123. 